\title{
Inventory Behavior and Financial Constraints: Theory and Evidence *
}

\author{
Sudipto Dasgupta, ${ }^{\dagger}$ Erica X.N. Li ${ }^{\ddagger}$ and Dong Yan ${ }^{\S}$
}

January 10, 2018

\begin{abstract}
We model the interaction of financial constraints, capacity constraints, and the response of production and inventory to cost and demand shocks. The model predicts that in response to favourable shocks, financially constrained firms are unable to build up inventory as rapidly as unconstrained firms. However, because the favourable shocks gradually ease the financial constraints, constrained firms continue to build inventory and eventually carry surplus inventory (relative to unconstrained firms) to unfavourable states. This allows them to deplete inventory more aggressively in response to unfavourable shocks. Our empirical evidence provides broad support for the model's predictions.
\end{abstract}

JEL Classification: G30, G31

Keywords: Inventory, Financial Constraints, Capital Investments

*We would like to thank David Denis (the editor) and an anonymous referee for comments that greatly improved the paper. We also benefited from discussions with Bo Becker, Mariassunta Giannetti, Jiasun Li, Laura Liu, Lei Mao, John Matsusaka, Abhiroop Mukherjee, David Reeb, Michael Roberts, Rik Sen, Per Strömberg, Baolian Wang, Ramona Westermann and comments from those attending presentations at the EFA (Lugano), FMA Asia (Shanghai), AsianFA (Bali), AFBC (Sydney), the Five-Star (Beijing) conference, Lancaster University and the University of New South Wales. We thank Xiaodan Gao for sharing her data on Just-in-Time adoptions and Ran Guo and Yuchen Sun for research assistance. Dasgupta gratefully acknowledges financial support from Hong Kong's Research Grant Council under grant number 641211. Li acknowledges the support from Cheung Kong Graduate School of Business. Yan acknowledges the support from Stockholm School of Economics and Swedish House of Finance. All errors are our own.

$\dagger$ Department of Finance, Chinese University of Hong Kong, Shatin, NT, Hong Kong; Lancaster University; and CEPR; Tel: (852) 39431913; E-mail: s.dasgupta@cuhk.edu.hk.

${ }^{\ddagger}$ Department of Finance, Cheung Kong Graduate School of Business, Beijing, China, 100738; Tel: (86)10 85378102; E-mail: xnli@ckgsb.edu.cn.

$\S$ Department of Finance, Stockholm School of Economics, Drottninggatan 98, 11160 Stockholm, Sweden; Tel: (46) 8 7369117; E-mail: Dong.Yan@hhs.se. 


\section{Introduction}

Inventory investment is widely regarded as an important contributor to business cycle fluctuations. Even though it constitutes less than 1 percent of GDP in advanced countries, aggregate inventory investment is 20 times more volatile than GNP and can account for as much as $87 \%$ of the drop in GNP during the average postwar recession in the United States (Blinder and Maccini (1991)). A less well-known fact is that among publicly traded firms in the U.S. between 1971-2010, the inventory investments of financially more constrained firms are $73 \%$ more volatile than those of financially less constrained firms. Financially constrained firms also hold $50 \%$ more inventory than the less constrained ones. Given that private firms are generally more financially constrained than public firms, financial constraint could potentially play an important role in generating the large volatility of aggregate inventory investments. However, how financial constraints affect inventory holdings has not been extensively studied in the literature, in contrast to the large literature on the effect of such constraints on capital investment.

Two of the earliest studies of the financial determinants of inventory holdings (Kashyap, Stein and Wilcox (1993) and Kashyap, Lamont and Stein (1994)) attempted to resolve the puzzling lack of evidence that the cost of finance (or the cost of carry for inventory) affects inventory behavior. Both papers found evidence that in recent U.S. recessions, a so-called "bank-lending channel" seemed to have affected the ability of bank-dependent and liquidity constrained firms to invest in inventory. Subsequently, Carpenter, Fazzari and Petersen (1994) (hereinafter CFP), using quarterly data from Compustat, demonstrated that during three sub-periods from 1981-1992 when monetary policy had a different stance in the U.S. and an inventory cycle was generated, corporate cash flows affected inventory behavior, and more so for financially constrained firms (smaller firms) than for unconstrained firms (larger firms). CFP interpreted this evidence as consistent with the idea that, when faced with a liquidity shortage, financially constrained firms are more likely to cut inventory investment than other types of investment (for example, investment in fixed assets 
or in R\&D) which are associated with larger adjustment costs (that is, are less flexible).

In this paper, we explore the effects of financial constraints on firms' inventory behavior..$^{1}$ We first present a model of inventory behavior in which production capacity, sales, and inventory holding decisions are simultaneously made by financially unconstrained as well as constrained firms. We calibrate the model to replicate observed differences in first and second moments of sales and inventory holdings (scaled by lagged capital) as well as changes in inventory, sales and capital (also scaled by lagged capital) between financially unconstrained and financially constrained firms. In particular, our model calibrations generate similar differences in the ratio of inventory holdings to lagged capital for constrained and unconstrained firms as in the actual data (median values of 16 and 24 percent, respectively, for financially unconstrained and constrained firms for the model generated data versus 22 and 30 percent in the Compustat data at quarterly frequency), and also similar differences between the two groups in the variability of inventory over lagged capital and inventory growth as in the actual data. Based on our model, we then derive several empirical implications of financially constrained behavior, test these implications on model-generated data, and then take the same tests to the real data. We find consistent results. An important feature of our tests is that, unlike most other tests of financially constrained behavior, we do not need to rely on cash flow sensitivities to interpret our results.

Our model builds on the notion that capital investment is not only associated with higher adjustment costs relative to inventory adjustment, but for financially constrained firms, capital is also difficult to rebuild. We thus augment the standard "linear-quadratic" mode 2 with both capacity and financial constraints and allow a role for both cost and demand shocks. Cost shocks

\footnotetext{
${ }^{1}$ Two recent papers model inventory as a factor of production together with capital. Jones and Tuzel (2013) study the effects of cost of capital on inventory investment and find that risk premium is negatively related to future inventory growth. They use risk premium to proxy for financial conditions and find results that are consistent with previous literature. Belo and Lin (2012) model inventory the same way as Jones and Tuzel (2013), but study the relation between stock returns and inventory growth rate. They find that firms with lower inventory growth rate outperform firms with higher inventory growth rate. Inventory adjustment costs are important in these models in explaining the return spreads between high and low inventory growth firms, following standard q-theory logic.

${ }^{2}$ See, for example, Ramey and West (1999), Section 3. CFP (1994) provide an excellent overview of the literature, including prior work on the effect of monetary policy on inventory holdings.
} 
have gained favor in the inventory literature as the phenomenon of producing more than sales when cost shocks are favorable and less than sales when cost shocks are unfavorable - known as production cost-smoothing behavior - is consistent with the widely documented fact that inventory movements are procyclical $]^{3}$ In contrast, demand shocks (in the absence of cost shocks) lead to countercyclical inventory movements when production costs are convex (over-produce relative to demand and build inventory when demand is low, and underproduce and sell from inventory when demand is high) and imply countercyclical inventory movements. However, as noted by Blinder (1986), if the stochastic process for demand shocks follows an $\operatorname{ARMA}(1,1)$ structure rather than the standard AR(1) structure, the procyclical behavior of inventory can be restored even when cost shocks are not extremely volatile $]^{4}$ Accordingly, we assume that cost shocks follow an AR(1) process, and demand shocks follow an ARMA(1,1) process.

In our model, due to capacity constraints and capital adjustment costs, financially unconstrained and constrained firms have different responses to cost and demand shocks. When favorable shocks occur, financially unconstrained firms can immediately finance capacity expansion to take advantage of these shocks. When they experience a favorable cost shock, they step up production and build up inventory so that they can sell from inventory in unfavorable cost shock states. When they receive favorable demand shocks, they step up production and inventory accumulation in anticipation of higher demand in the subsequent periods. Financially constrained firms, on the other hand, not only have somewhat different incentives, their ability to respond to

\footnotetext{
${ }^{3}$ For manufacturing firms, cost shocks can originate in shocks to input prices, e.g. prices of energy inputs, productivity shocks to input suppliers, or exchange rate fluctuations. An extensive literature documents the importance of input price shocks for aggregate economic fluctuations (see, for example, Bruno and Sachs (1982)). Eichenbaum (1989) finds evidence consistent with production-cost smoothing and the importance of cost shocks for inventory behavior. Blanchard (1983), Durlauf and Maccini (1995), Ramey (1989) and West (1986) all emphasize the importance of cost shocks for inventory behavior. A recent paper by Wang and Wen (2011) develops a General Equilibrium model based on production-cost smoothing behavior that is consistent with many stylized facts regarding aggregate inventory fluctuations.

${ }^{4}$ The intuition for this is that the effect of the innovation in the ARMA process can get stronger in the short run if the sum of the autoregressive coefficient and the moving-average coefficient is larger than one. In that case, demand is expected to be higher next period if it is high this period - this causes firms to build up inventory in anticipation of future sales when they experience positive demand shocks.
} 
these shocks is also limited. Both of these lead to markedly different inventory investment behavior for these firms. First, due to capacity constraints made tighter due to their inability to raise financing and increase production capacity quickly, financially constrained firms are only able to build up inventory gradually in response to both favorable cost and demand shocks. However, as their profits increase following these favorable shocks and they are able to invest more in capacity, the financially constrained firms actually go through a phase of more sustained inventory growth than their unconstrained counterparts, and carry more inventory to the bad shock states. This is because inventory, for the financially constrained firms, is also a buffer against future adverse shocks. Unlike the unconstrained firms who can borrow from the capital market to cover their operating losses when hit with adverse shocks, the financially constrained firms must sell assets to tide over such periods. Since capital is costly to adjust and rebuild, the financially constrained firms have stronger incentives to accumulate inventory when production costs are low, and to sell from inventory in adverse states rather than engage in asset sales.

These differences in the inventory investment behavior of unconstrained and constrained firms manifest in the way these two types of firms respond to favorable and unfavorable cost and demand shocks. First, in response to both favorable cost and demand shocks, while both types of firms immediately step up inventory accumulation, the immediate response of financially constrained firms is more muted than that of their unconstrained counterparts. However, financially constrained firms' inventory accumulation in response to these shocks is more prolonged, and they carry more inventory to adverse shock states than the unconstrained firms. In these adverse shock states, while both types of firms reduce inventory accumulation and possibly deplete inventory, financially constrained firms do so more aggressively and in a more sustained manner than the unconstrained firms. In other words, we expect the relative sensitivity of the response of constrained firms vis-a-vis the unconstrained firms to be asymmetric in the short-term, with constrained firms responding more sluggishly to favorable shocks but more aggressively to unfavorable shocks. However, this asymmetry would no longer exist over a longer period, and constrained 
firms would eventually accumulate (deplete) more inventory than unconstrained firms in response to favorable (unfavorable) shocks.

We first demonstrate the asymmetric response for our calibrated model-generated data via regressions of inventory growth on the cost and demand shocks. We also show that the asymmetry disappears in the longer term, with constrained firms accumulating more inventory in response to favorable shocks, and depleting more inventory in response to adverse shocks. We then take the model to actual firm level data on inventory behavior. Since proxies for demand shocks are not readily available, we focus on cost shocks $5^{5}$

Indices of input prices at the industry level at the annual frequency can be obtained from the Bureau of Economic Analysis (BEA). Using percentage change of the input price index as a proxy for firm level cost shocks, for inventory growth at the annual frequency as the dependent variable, we find that constrained firms adjust inventory more slowly to favorable cost shocks, but do so more aggressively for unfavorable shocks. These results hold for each of four commonly used measures that classify firms as financially constrained/unconstrained, namely, firm size, availability of bond or commercial paper ratings, the Hadlock-Pearce Index, and the Whited-Wu Index.

To examine the dynamics of inventory adjustment implied by our model, we require input price changes at higher frequency. Unfortunately, the quarterly price indices from BEA are available only at the sector level (15 industry groups) from 2005. Therefore, we focus on commodity prices, which directly and indirectly affect the cost of production of firms in many different industries, and for which we have a relative long time series. We focus on three commodities: oil, gold, and silver. Our model shows that sales growth responds positively to the favorable shocks, and that inventory growth responds to sales growth in the same way as it does to the shocks for constrained and unconstrained firms. Commodity prices affect, directly or indirectly, the cost of production

\footnotetext{
${ }^{5}$ Since we do not have a prior on which shock, demand or cost, is more important to sales growth, we calibrate the parameters of the shock processes so that demand and cost shocks contribute equally to sales growth. Under this calibration, the simulated data shows that while the effects of cost and demand shocks on inventory changes are qualitatively similar, the former is the main driver of changes in inventory investments.
} 
of firms in many industries. Accordingly, we first identify those industries in which quarterly sales growth is sensitive to the negative of the quarterly change in the price of the commodity in question, and focus attention on these industries. We find that for all three of the commodities, sales growth responds to the change in price with a lag of two quarters. To further ensure that we are correctly identifying the impact of cost shocks generated by changes in commodity prices, we instrument quarterly sales growth with quarterly change in each of the commodity prices lagged by two quarters, and test whether inventory growth responds to instrumented sales growth in a manner predicted by our model. We find consistent evidence.

We get similar results using a time series of quarterly input price changes at the industry-level that we construct based on the inter-industry Input-Output table and output prices based on the Producer Price Index (PPI) provided by the Bureau of Labor Statistics. We calculate the percentage of inputs from each supplier industry to the total inputs of the customer industry, and use this to weigh the output price indices of the supplier industries to construct the index for the supplier industry's input price. We use an approach very similar to that described above for commodity prices and instrument firm sales growth by the percentage change in input price change lagged by two periods. Our results for the response of inventory growth to instrumented sales growth are similar and consistent with the predictions of the model.

Since firm characteristics such as firm size that determine whether a firm is classified as financially constrained/unconstrained could directly affect inventory behavior (and not only via the financial constraint channel), we also examine inventory behavior around an event that provided exogenous variation to the degree of financial constraint faced by a group of firms. Lemmon and Roberts (2010) show that three near-concurrent events in 1989 (the Collapse of Drexel Burnham Lambert, Inc., the passage of the Financial Institutions Reform, Recovery, and Enforcement Act of 1989 (FIRREA), and a change in the National Association of Insurance Companies (NAIC) credit rating guidelines) led to a major contraction of the availability of external financing for below-investment-grade firms. To understand how an exogenous change in financing constraint 
affects inventory investment vis-a-vis firms that are not exposed to such a change, in a differencein-difference setting, we compare the inventory investment behavior for a set of below-investmentgrade firms before and after the credit shock with that of matched unrated firms. We do this test for two sets of firms: (i) those that are exposed to a favorable (below industry time-series median) annual input price change for the three years before the credit shock as well as the three years after, and (ii) those that are exposed to an unfavorable annual input price change. We find that the quarterly inventory growth for the firms exposed to the credit shock is lower when they experience favorable input price change in the last three quarters of 1990 - consistent with a more sluggish response by financially constrained firms as implied by our model. However, if the window is extended to the fourth quarter of 1993, the difference becomes much smaller, also consistent with the model. For firms exposed to unfavorable shocks, we find that the credit shock-exposed firms deplete inventory holdings at a faster pace than the matched unexposed firms, and the difference widens over the longer horizon. We perform a similar experiment, again following Lemmon and Roberts (2010), based on the idea that the severity of the shock was more important for firms headquartered in the Northeast, since bank lending contracted much more sharply in that region during 1990 and 1991 due to declining real estate prices and consequent erosion of bank capital. We get quantitatively very similar results.

In summary, we make four major contributions. The first is to explicitly model capital accumulation, and the interaction between production capacity and inventory accumulation, previously unmodelled in the literature. The second is to model and examine the effect of financial constraints on this interaction. Similar to the informal arguments in CFP, our model captures the idea that when faced with poor profitability, financially constrained firms without access to external financial markets may prefer to liquidate inventory rather than capital. While CFP test their hypothesis in terms of cash flow coefficients, we derive and test a different implication which does not require us to rely on the interpretation of cash flow coefficients, an issue that has been the subject of much debate in recent literature. Herein lies our third contribution. Finally, we attempt 
to isolate several factors that affect inventory holding behavior both in the presence and absence of financial constraints, and in the process, suggest possible reasons for the much higher inventory holdings of constrained firms. This is an issue that, unlike cash holdings, has been completely untouched in recent literature, and could potentially be tested with suitable firm-level constructs.

The paper is organized as follows. Section 2 introduces the model and explores the implications. Sections 3 explains the sample. Section 4 shows our main empirical findings from actual and simulated sample. Section 5 presents the results when we use input price changes at quarterly frequency to instrument sales growth. Section 6 examines inventory behavior around an event that provided exogenous variation to the degree of financial constraint faced by a group of firms. Section 7 discuss the robustness of our results when firms could hedge their shock and accumulate cash holdings. Finally, Section 8 concludes.

\section{The Model}

The firm's production technology is described by the following equations:

$$
\begin{aligned}
Q_{t} & \leq A_{0} A_{t}^{1-\alpha} K_{t-1}^{\alpha}, \\
C_{Q t} & =e^{Z_{t}}\left[d_{1} Q_{t}+\frac{d_{2}}{2 A_{t}} Q_{t}^{2}\right], \\
Y_{t} & =e^{X_{t}}\left(1-\frac{h S_{t}}{A_{t}}\right) S_{t},
\end{aligned}
$$

where $Q_{t}$ is the output level, which is bounded above by the capacity/capital $K_{t-1}$ at the beginning of period $t$ and the aggregate productivity level $A_{0} A_{t}$ with $A_{0}$ being a constant scaling factor. Based on the optimal choice of output level $Q_{t}$, we define the utilitization rate of capacity as $\nu_{t}=\left(\frac{Q_{t}}{A_{0} A_{t}^{1-\alpha}}\right)^{1 / \alpha} / K_{t-1}$. Production incurs time-varying linear costs and quadratic costs $C_{Q t}$, where $Z_{t}$ is the cost shock and $d_{1}$ and $d_{2}$ are constants. The appearance of $A_{t}$ in equations (2) and (3) is to ensure balanced growth, which will be explained later. In equation (3), $Y_{t}$ and $S_{t}$ 
refer to sales in dollars and in units of quantity, respectively, $X_{t}$ is the demand shock, and $h$ is the constant slope of the demand curve.

There are two exogenous shocks in our model, idiosyncratic cost and demand shocks. We also assume a constant growth trend in productivity $A_{t}$, i.e., $A_{t}=g^{t}$, to match the time trend in sales and inventory $!^{6}$ Cost shocks play an important role in explaining the phenomenon of producing more than sales when cost shocks are favorable and less than sales when cost shocks are unfavorable, known as production cost-smoothing behavior (Eichenbaum, 1989). This behavior is also consistent with the widely documented fact that inventory movements are procyclical. Demand shocks can also lead to production-smoothing behavior when production costs are convex (over-produce relative to demand and build inventory when demand is low, and underproduce and sell from inventory when demand is high). However, demand shocks following the commonly used AR(1) process would imply countercyclical inventory movements. Blinder (1986) shows that if demand shocks follow an $\operatorname{ARMA}(1,1)$ structure, the procyclical behavior of inventory can be restored. The reason is that the effect of the innovation in the ARMA process can get stronger in the short run if the sum of the moving-average coefficient and the autoregressive coefficient is larger than one. In that case, demand is expected to be higher next period if it is high this period. In anticipation of higher future sales, firms build up inventory when they experience positive demand shocks, resulting in procyclicality. Following Blinder (1986), we thus assume that cost shocks follow an $\mathrm{AR}(1)$ process, and demand shocks follow an $\operatorname{ARMA}(1,1)$ process.

The cost shocks follow an $\operatorname{AR}(1)$ process specified as: $Z_{t+1}=\rho_{Z} Z_{t}+\sigma_{Z} \varepsilon_{t+1}^{Z}$, where $\rho_{Z}$ is the autocorrelation coefficient and $\varepsilon_{t+1}^{Z}$ is an i.i.d. standard normal variable uncorrelated across firms. The demand shocks follow an $\operatorname{ARMA}(1,1)$ process specified as: $X_{t+1}=\bar{X}+\rho_{X}\left(X_{t}-\bar{X}\right)+\rho_{\varepsilon} \varepsilon_{t}^{X}+$ $\varepsilon_{t+1}^{X}$, where $\varepsilon_{t+1}^{X}$ is an i.i.d. random variable with standard deviation of $\sigma_{X}$, which is uncorrelated across firms and with $\varepsilon_{t+1}^{Z}, \rho_{X}$ is the persistence, $\rho_{\varepsilon}$ is the moving average coefficient, and $\bar{X}$ is

\footnotetext{
${ }^{6}$ Because our paper focuses on the cross-sectional differences in inventory behavior, aggregate productivity shocks are not critical. For simplicity, we assume no aggregate productivity shocks and thus a constant discount rate. We also solve a version of the model with aggregate shocks and our main results hardly change. The results are available upon request.
} 
the long-run average of the demand shock and is a scaling factor in the model.

Following Blanchard (1983), we assume quadratic stockout avoidance costs for inventory holdings, i.e.,

$$
C_{N t}=\frac{b}{2}\left(\frac{S_{t}}{A_{t}}\right)^{\gamma}\left(1-\frac{c N_{t}}{S_{t}}\right)^{2}
$$

where $\gamma$ measures the elasticity of the stockout avoidance costs to sales and $N_{t}$ is the inventory level whose change follows the identity

$$
Q_{t}=S_{t}+N_{t}-N_{t-1}
$$

The constant $b$ measures the magnitude of the stockout costs and $c$ refers to the sales-to-inventory ratio that results in zero stockout costs. Again, we include $A_{t}$ in the cost function to impose balanced growth. The quadratic stockout avoidance cost function reflects the manifestation of two types of costs: the first is the physical cost of carrying inventory, which is an increasing function of the level of inventory; the second is the expected cost of stocking out, which is a decreasing function of the level of inventory given sales, as a higher inventory-to-sales ratio decreases the probability of stocking out. The overall cost decreases initially in the level of inventory as the likelihood of stockout decreases, and then eventually increases in the level of inventory when the cost of holding inventory dominates.

The law of capital accumulation follows $K_{t}=(1-\delta) K_{t-1}+I_{t}$, where $\delta$ is the depreciation rate and $I_{t}$ is the investment made at time $t$. Investment incurs quadratic adjustment costs, given by $C_{I t}=\frac{a}{2}\left(I_{t} / K_{t-1}\right)^{2} K_{t-1}$, where $a$ is a positive constant. The firm, as a going concern, pays fixed and variable operating costs, where the latter depends on the production capacity, and operating costs are given by $C_{O t}=A_{t}\left[f_{0}+f_{1}\left(\frac{K_{t-1}}{A_{t-1}}\right)\right]$, where $f_{0}$ and $f_{1}$ are constants and the appearance of $A_{t-1}$ is to ensure balanced growth. Because of the variable costs of capacity, the firm has an incentive to decrease capacity during bad times. 
For simplicity, we assume that the firm is an all-equity firm. Shareholders maximize firm value, which is given by the following optimization problem:

$$
V_{t}\left(K_{t-1}, N_{t-1}, X_{t}, Z_{t}\right)=\max _{\left\{Q_{t}, N_{t}, I_{t}\right\}}\left\{D_{t}+\beta \mathbb{E}_{t}\left[V_{t+1}\right]\right\}
$$

where $D_{t} \equiv Y_{t}-C_{O t}-C_{Q t}-C_{N t}-C_{I t}-I_{t}$ is the dividend payment, the discount rate $\beta$ is assumed to be constant for simplicity, and the maximization is subject to the constraint defined by equation (5).

We solve the model for two types of firms: (1) financially unconstrained firms who can seek external financing with no costs; (2) financially constrained firms whose dividend has to be nonnegative. Both constrained and unconstrained firms face the same optimization problem described by equation (6), except that the optimization problem of constrained firm is solved subject to an additional constraint $D_{t} \geq 0$. Our setup is a simple way to model firm heterogeneity in external financing costs, which could be due to reasons such as information asymmetry and asset tangibility. Gomes, Yaron and Zhang (2003) and Belo, Lin and Yang (2016), among others, provide microfoundation for heterogeneity in financing costs. In Gomes, Yaron and Zhang (2003), debt capacity depends on the net wealth of entrepreneurs due to costly state verification. In Belo, Lin and Yang (2016), debt capacity is limited by the asset value due to collateral constraints. In those models, firm size becomes a natural proxy for financial constraint. In our model, we do not take a stand on where firm heterogeneity in financial costs originates from. Differences in firm characteristics such as size among firms with different financing costs arise endogenously. More important, when we analyze the behavior of the firms we model, we do not need to reply on observed firm characteristics to classify constrained and unconstrained firms, which allows us to isolate the effect of financing costs from other factors such as profitability.

Since our model has four state variables, including two firm-specific shocks, capital level, and inventory level at the beginning of the period, and three endogenous choice variables, including 
capital investment, inventory investment, and output (which could be less than the capacity), the commonly used solution method, value function iteration, suffers from the curse of dimensionality. Following Imrohoroglu and Tuzel (2014), we solve firms' optimal production, inventory holding, and investment policies using the perturbation method. The details of the solution method are included in Appendix A.

\subsection{Remarks on the Model}

The assumption of convex production costs, though reasonable for manufacturing industries, is in fact not required for our main results. Blinder (1986) shows that with increasing marginal costs, production smoothing rather than production-cost smoothing occurs, so that firms accumulate inventory when demand is low and deplete inventory when demand is high, leading to counter-cyclical inventory behavior. However, a sufficient variance in cost shocks combined with an $\operatorname{ARMA}(1,1)$ stochastic process for demand shock (or one in which demand builds up at first and then decays) is sufficient to generate pro-cyclical behavior $7^{7}$ Thus, our results would continue to hold with constant or decreasing marginal costs. Such an assumption would also be meaningful for some other sectors of the economy, such as the Retail sector 8 However, we retain the assumption of increasing marginal cost because manufacturing firms still constitute the bulk of our sample $(60 \%)$ and it is important that our calibration exercise addresses the most important segment of the economy.

\footnotetext{
${ }^{7}$ When demand shocks follow an $\operatorname{ARMA}(1,1)$ process, the effects of a positive innovation $\varepsilon_{t}^{X}$ on the demand in the subsequent periods are $\left(\rho_{X}+\rho_{\varepsilon}\right), \rho_{X}\left(\rho_{X}+\rho_{\varepsilon}\right), \rho_{X}^{2}\left(\rho_{X}+\rho_{\varepsilon}\right)$, etc. That is, the response of demand to an innovation first builds up and then decays. Expecting a better demand next period after a positive innovation, firms tend to build up inventory to sell in the future.

${ }^{8}$ In fact, Blinder (1981) provides evidence that (1) changes in inventory of retail sectors are as important as those of manufacturing sectors in terms of magnitude and the contribution to business cycle (see, Table 4); (2) two facts hold for both manufacturing and retail sectors: (a) variance of production is larger than the variance of sales (Tables 12,13); (b) correlation of sales and changes in inventory is positive or zero (Table 13). Further, for retailers, changes in the purchase price of goods is a key driver of inventory behavior. Thus it seems that the behavior of inventory investment in manufacturing and retail sectors are not very different, at least in the aspects that we are interested in.
} 
Further, the input $K$ called "capital" in the model can be interpreted fairly broadly to represent any factor of production that (a) limits production capacity in the short term, (b) entails costly expenditure to build up, and (c) is costly to adjust. As such, it is not limited to represent the stock of plant and machinery only, but also encompasses skilled labor (for firms in the high-tech sector), number of stores or retail outlets, or warehouse capacity (for firms in the Retail or Wholesale sector). Thus, we exclude only Financial firms and Utilities in our empirical analysis.

Our model is perhaps most directly relevant for finished goods inventories. However, it is not difficult to see that the qualitative properties for inventory behavior are likely to extend to intermediate goods inventories as well. When intermediate inputs are cheap (corresponding to favorable cost shocks), firms in the model produce more and accumulate more finished goods inventory, However, if there are production lags, or economies of scale in delivery of intermediate input: 9 , intermediate goods inventory will increase as well. Some intermediate goods inventory (or work-in-progress inventory) will be directly created by the firm in the process of transformation of purchased inputs to output. Since financially constrained firms need to allocate their internal profits to capacity investment and purchase of intermediate inputs, they will initially lag behind their unconstrained counterparts in terms of investment in intermediate inputs, but will go through a longer spell as capacity expands. In the same way, in adverse states, they use up accumulated intermediate inventory rather than purchase new intermediate inputs, and do so more aggressively than unconstrained firms. Also worth recalling in this context is the "invisible hand" argument (Blanchard, 1983), which suggests that if cost shocks are common across producers and users of intermediate goods, then firms will invest in intermediate goods inventory precisely when costs are low and their producers are producing more, and they will be depleted when costs go up and producers produce less. Thus, investment in intermediate goods inventories should also be procyclical, and constrained firms may have a stronger incentive to cut investment in intermediate goods inventory in bad times (and therefore buffer up in good times, since they need to produce

\footnotetext{
${ }^{9}$ See Blinder (1981) for discussions of the importance of economies of scale in delivery.
} 
in bad times to generate sales revenue, for which intermediate inputs are necessary). Modelling the invisible hand mechanism would require an aggregative approach which is beyond the scope of this paper.

\subsection{Calibration}

We calibrate the model at quarterly frequency. Table 1 presents the parameter values used in the calibration. Our calibration strategy is as follows. The capital-to-output ratio $\alpha$ is set to 0.7 to be consistent with the estimate in Hennessy and Whited (2007). The growth rate of productivity $g$ is 1.009, chosen to match the average aggregate growth rate of sales in our sample. Since we assume risk-neutrality in the model, the discount rate is the risk-free rate, given by $\frac{1}{\beta g}$. The discount factor $\beta$ is hence set to 0.982 to generate a quarterly interest rate of $0.91 \%$. In equilibrium, the average investment-to-capital ratio is given by $1-(1-\delta) / g$ in the model. Capital depreciation rate $\delta$ is then chosen to match the quarterly investment-to-capital ratio of 0.024 in our sample period. Investment adjustment cost parameter $a$ is chosen to match the volatility of investmentto-capital ratio. The slope of the demand curve $h$ is chosen to generate an average markup of $20 \%$, consistent with the calibration in Altig et al. (2011). The scaling factor $A_{0}$ in the capacity constraint is chosen to match the average capacity utilization rate of $80 \%$ for the sample period $1971-2010 \sqrt{10}$ The stockout avoidance cost ratio $c$ is set to 2.08 to match the mean of inventoryto-capital ratio. The long-run mean of demand $\bar{X}$ is a scaling factor and is chosen so that the average capital level is one.

To pin down the values of the volatilities of idiosyncratic demand and cost shocks $\sigma_{X}$ and $\sigma_{Z}$, we match the time-series average of the cross-sectional standard deviation of sales-to-capital ratio (0.134 vs. 0.157 in simulated and real data). Since we do not have a prior on the relative magnitude of the volatilities of demand and cost shocks, we assume that both shocks contribute

\footnotetext{
${ }^{10}$ The capacity utilization data is from the IHS Global Insight dataset.
} 
equally to the variations in sales growth 11

The remaining 9 parameters, the stockout avoidance cost parameter $b$, elasticity of stockoutavoidance cost to sales $\gamma$, production cost parameters $d_{1}$ and $d_{2}$, the persistences of idiosyncratic cost and demand shocks $\rho_{Z}$ and $\rho_{X}$, the moving average coefficient $\rho_{\varepsilon}$, and the operating cost parameters $f_{0}$ and $f_{1}$, are chosen to match the means and volatilities of sales-to-capital ratio, sales change-to-capital ratio, and inventory change-to-capital ratio, the volatility of inventoryto-capital ratio, the autocorrelations of sales-to-capital ratio, and the ratio of the volatility of aggregate output to the volatility of aggregate sales ${ }^{12}$ In total, we have 20 parameters to match 20 moments in the data.

We simulate 100 panels, each with 1440 quarters and 600 firms, half of which are financially constrained and the other half are financially unconstrained. For each panel, the simulation starts from the steady state values of the state variables. We drop the first 720 quarters to ensure that the simulated economy has reached the equilibrium. The same regressions applied on the real data are conducted for each simulated panel separately. The reported regression coefficients and the associated t-statistics are computed using the Fama-MacBeth method, i.e.,

$$
\beta=\frac{1}{N} \sum_{i=1}^{N} \beta_{i} \quad \sigma(\beta)=\sqrt{\sum_{i=1}^{N} \frac{\left(\beta_{i}-\beta\right)^{2}}{N}} \quad t=\frac{\beta}{\sigma(\beta) / \sqrt{N}}
$$

where $i$ refers to the $i^{\text {th }}$ simulated panel.

\footnotetext{
${ }^{11}$ Specifically, we choose $\sigma_{X}$ and $\sigma_{Z}$ so that the following two regressions have similar R-squared: $S \_G r o w t h_{t}=$ $\alpha+\beta_{1}$ CostShock $_{t}+\beta_{2}$ CostShock $_{t} \times F C+\varepsilon_{t}$ and S_Growth S $_{t}=\alpha+\beta_{1}$ DemandShock $_{t}+\beta_{2}$ DemandShock $_{t} \times F C+\varepsilon_{t}$.

${ }^{12}$ Blinder (1986) shows that the ratio of the volatility of aggregate output to the volatility of aggregate sales for all manufacturing industry is 1.14 , while this ratio is 1.13 in our simulated data.
} 


\subsection{Key Model Ingredients and Hypotheses Development}

\subsubsection{The Determinants of Inventory Holdings}

Little is known about the cross-sectional determinants of inventory holdings, and even less as to why financially constrained firms hold 50 percent more inventory as a proportion of lagged capital than do unconstrained firms, and exhibit higher volatility of inventory holdings. To gain intuition about the model and these questions, we conduct comparative static exercises on the model-generated inventory holding levels and its volatility by changing four key parameters of the model ${ }^{13}$ We report the effects of parameter changes - one at a time - on both the mean level of inventory holding (inventory over lagged capital) for each type of firm, as well as the standard deviation of the same variable (within square brackets).

Given a negatively sloped demand curve and stochastic and upward sloping marginal cost curve, firms have a natural incentive to produce more when the marginal cost curve is lower, and carry inventory for sale to periods when it is higher. This incentive for inventory accumulation exists for both unconstrained and constrained firms and leads to procyclical inventory investments. However, such sales-smoothing (or production cost smoothing) behavior is more important for the latter because in the bad cost states, when profits are low, they face the risk of having to sell capital or adjust capital investment too drastically, which is costly. If they manage to carry inventory produced in good cost (high profit) states to bad cost (low profit) states, they can avoid costly capital adjustment by generating sales via depletion of inventory instead. This incentive to buffer inventory exists for positive demand shocks as well. These shocks are associated with higher profits, which allows financially constrained firms to expand production capacity. As capacity builds up. these firms are able to expand production beyond their intended immediate sales and carry an inventory buffer into less profitable states.

Thus, any parameter that affects the likelihood of operating losses in the unfavorable cost or

\footnotetext{
${ }^{13}$ In the working paper version of the paper, we report comparative statics results for a larger set of model parameters, including slopes of marginal cost and marginal revenue curves.
} 
demand states will affect inventory and investment behavior of constrained firms more than that of unconstrained firms. We first focus on fixed operating costs, $f_{0}{ }^{14}$

Table 2 reports our comparative static results. We report, for each parameter change, the mean levels and the mean of the time-series standard deviations for inventory $(N)$, capital $(K)$, and the inventory to capital ratio $\left(\frac{N}{K}\right)$ for unconstrained and constrained firms. The time-series standard deviations are reported inside square brackets. To facilitate comparison, all values for the mean and standard deviation in Table 2 for inventory and capital are expressed as percentages of the corresponding values for financially unconstrained firms at the baseline parameter values.

In column (1) of Table 2 , we find that if we raise $f_{0}$ from its baseline value of 0.0665 to 0.076 , there is no effect on the capital investment or inventory holdings of the financially unconstrained firms. This is because the unconstrained firms do not accumulate inventory with the objective of avoiding capital depletion in bad states. However, the constrained firms do. So when this parameter becomes higher, the constrained firms reduce capital and increase inventory. Therefore, the inventory-to-capital ratio increases for the financially constrained firms from 0.225 to 0.269.

Next, we consider the capital adjustment cost parameter $a_{0}$. Investment is less flexible than inventory because it is associated with adjustment cost. When these adjustment costs increase (larger $a_{0}$ ), firms are discouraged from investing in capital. This is seen in column (2). Inventory holdings also decrease, because capital and production decrease. The inventory-to-capital ratio, however, is higher for both types. Moreover, it increases much more for constrained firms, consistent with the idea that when investment adjustment costs are higher, cutting capital in bad states is even more costly for these firms, so that it is more important to carry inventory to bad states.

Next, we consider the effect of higher cost uncertainty. Without cost uncertainty, there is no reason for production cost smoothing. In column (3), we examine the effects of higher cost volatility. Higher cost volatility causes unconstrained firms to invest more in capital[5. However,

\footnotetext{
${ }^{14}$ The baseline value of $f_{0}$ implies that fixed operating costs are 21 percent of production costs.

${ }^{15}$ Since capital is costly to adjust, and firms gain more from increasing output when cost is low than they lose
} 
the constrained firms do not increase capital - because operating cost $f_{1}$ increases in capital, they are conservative about increasing capital stock in good cost states as it would be costly to hold excess capacity or adjust capital down in bad cost states. Thus, the gap in capital stock between the unconstrained and constrained firms widens. However, constrained firms increase inventory much more than the unconstrained firms, since with greater volatility, the risk of more severe bad cost states increases, requiring more inventory to be carried over into these states as a buffer. Consequently, the inventory-to-capital ratio of constrained firms increases, whereas that of the unconstrained firms decreases, when cost shock volatility is higher.

Finally, in column (4), we examine the effect of higher demand volatility. The effects are very similar to those for higher cost volatility. In particular, the unconstrained firms increase capital investment, and their ratio of inventory to capital falls. In contrast, there is little effect on capital investment by constrained firms. The latter firms now face a higher likelihood of operating losses and so respond by carrying a higher inventory buffer. As a result, their inventory to capital ratio increases.

To summarize, the following factors widen the gap in the ratio of inventory holdings to capital between financially constrained and unconstrained firms: (a) higher operating costs, (b) higher capital adjustment costs, and (c) higher volatility of cost and demand shocks. Moreover, there are two key observations about the volatility. First, the volatility of inventory of financially constrained firms is much more sensitive in general to the parameter changes than that for the unconstrained firms. Second, parameter changes that increase investment reduce the volatility of inventory. This second observation also explains the first one: because they operate under tighter capacity constraints, financially constrained firms take longer to build an inventory buffer, which leads to greater volatility in inventory holdings.

from cutting output when cost is high, they increase investment on average when cost volatility increases. 


\subsubsection{The Asymmetric Response of Inventory to Shocks}

Drawing from the above discussion, the key drivers of the difference in the inventory behavior of financially constrained and unconstrained firms are the following: (i) production cost smoothing behavior, which causes both types of firms to produce more when cost states are favorable and carry inventory to states when cost states are unfavorable, (ii) inventory build up in anticipation of sustained surge in demand following favorable demand shocks (iii) capital adjustment costs which provide additional incentive to financially constrained firms to build up inventory (or deplete less inventory in favorable states and carry that to unfavorable states, and (iv) capacity constraints that limit the ability of financially constrained firms to quickly build up inventory in response to favorable shocks. These four factors generate a set of unique predictions from our model. Unlike unconstrained firms who have more physical capital and can immediately access external financial markets to build capacity, financially constrained firms can build up capital and inventory less rapidly, and only do so as profitability improves in response to a persistent favorable shock. However, because constrained firms have larger needs to carry inventory to unfavorable states, they eventually accumulate more inventory as the good state persists. On the other hand, when the shock is adverse, as discussed above, constrained firms have a stronger incentive to liquidate inventory than do unconstrained firms immediately, and this effect also persists for a few periods. Thus, while the difference in sensitivity of inventory growth to cost shocks between financially constrained firms and unconstrained firms in the short-term will be asymmetric, with constrained firms responding more sluggishly to favorable shocks but more aggressively to unfavorable shocks, this asymmetry would no longer exist over a longer period, and constrained firms would eventually accumulate (deplete) more inventory than unconstrained firms in response to favorable (unfavorable) shocks.

Based on the above, we propose the following hypothesis.

Hypothesis Compared to financially unconstrained firms, financially constrained firms (1) 
deplete inventory more rapidly in reaction to unfavorable shocks; (2) accumulate inventory less rapidly in reaction to favorable shocks; however (3) as the good state persists, they accumulate more inventory eventually.

Next, we verify our hypothesis in both the simulated and actual data.

\section{Sample}

\subsection{Actual Data and Variables}

Our actual data sample consists of firms listed in the Compustat Industrial Quarterly Files at any point between 1971 and 2010. Following standard practice, we exclude financial, insurance, and real estate firms (SIC code 6000-6900), and utilities (SIC code 4900-4999). We exclude from the sample any firm-quarter observation that has missing book value of asset, sales or inventory. We also restrict the sample to firms with at least five consecutive years of data. All dollar values are converted into 2000 constant dollars. Firm characteristics, such as sales (scaled by lagged capital) and inventory (scaled by lagged capital) are winsorized at 1\% level at both tails of the distribution to alleviate the impact of outliers. In addition, we drop firms with total asset less than 15.5 million (in 2000 constant dollars) following CFP. The final dataset is an unbalanced panel consisting of 285,075 firm-quarter observations.

Inventory $\left(N_{t}\right)$ in our study is given by Compustat data item INVTQ, which includes raw materials, finished goods, work-in-progress and other inventory. ${ }^{16}$ In addition, to correct the bias that inventory stock value is understated under LIFO and overstated under FIFO, following CFP, we apply an algorithm developed by Michael Salinger and Lawrence Summers to adjust for LIFO (last in, first out) and FIFO (first in, first out) accounting. 17

\footnotetext{
${ }^{16}$ Unfortunately, disaggregated inventory series are only available in Compustat with sufficient coverage from the year 2004. When we repeat our baseline results on the disaggregated series, we get qualitatively similar results.

${ }^{17}$ For more detailed description of the adjustment method, please refer to Salinger and Summers (1983) and the appendix of CFP. Our results are robust if we do not adjust for FIFO and LIFO.
} 
Capital $\left(K_{t}\right)$ is defined as total asset (ATQ) minus inventory. This is because capital stock in the model does not include inventory. ${ }^{18}$ Sales $\left(S_{t}\right)$ in the actual data is the level of net sales (SALEQ). Cash Flow $\left(C F_{t}\right)$ is calculated as the sum of earnings before extraordinary items (IBQ) and depreciation (DPQ) scaled by lag capital. Investment $\left(I_{t}\right)$ is the quarterly capital expenditure calculated by converting the Compustat Year-To-Date item CAPXY to quarterly frequency.

Ratios including $N / K, S / K, I / K$ and $C F / K$ are all scaled by lagged capital. N_Growth and S_Growth are defined as change in the levels of inventory or sales (in 2000 constant dollars) from year $t$ to year $t-1$, scaled by capital in year $t-1$.

We use the reported fiscal quarter end to assign fiscal quarters with calendar quarters. Following CFP(1994) and Carpenter, Fazzari and Petersen (1998), in cases where the end of a fiscal quarter does not coincide with the end of a calendar quarter, we adjust the data so that the majority of the fiscal quarter is assigned to the appropriate calendar quarter.

\subsection{Financially Constrained Firms}

The literature on financial constraints offers many different measures to identify financially constrained firms in the actual data. Some of our results are based on ex ante classification of firms as financially constrained or unconstrained. Firm size is one of the most commonly used and relatively non-controversial. In each quarter, we rank firms according to the book value of asset at the beginning of the period and assign the top $30 \%$ to the financially unconstrained group (UFC), while the bottom $30 \%$ to the financially constrained group (FC). We also report results for three other commonly used financial constraint classifications, based on whether the firm has ratings, the Hadlock-Pierce Index (Hadlock and Pierce (2010)), and the Whited-Wu Index (Whited and $\mathrm{Wu}(2006))$. In addition, since firm characteristics such as firm size that determine whether a firm is classified as financially constrained/unconstrained could directly affect inventory behavior (and

\footnotetext{
${ }^{18} \mathrm{All}$ our results are robust if we use total asset or property, plant and equipment as capital.
} 
not only via the financial constraint channel), we examine inventory behavior around an event that provided exogenous variation to the degree of financial constraint faced by a group of firms.

Detailed variable constructions are discussed in Appendix B.

\subsection{Comparing Actual and Simulation Samples}

Table 3 reports summary statistics for the actual and simulation samples for the variables which are either targeted for our calibration, or are key regression variables 19 For all variables, the simulation preserves the order of the first moment, i.e., in every case, if the mean is higher (lower) for unconstrained firms in comparison to constrained firms in the actual data, this is also the case in the simulated data. With two exceptions, this is also the case for the second moments ${ }^{20}$

The table shows that we are able to obtain a reasonable match between the first and second moments of the target variables in the real data and the simulated data. It is important to emphasize that financially constrained and unconstrained firms differ in our model only in one dimension, namely, the degree of financial constraint. It is possible to argue, however, that these firms would differ in many other dimensions, which potentially could improve our calibration exercise. Hennessy and Whited (2007), for example, estimate parameters for small firms and large firms separately, and find that these firms differ in many dimensions. However, we choose not to go in that direction because we want to identify, as clearly as possible, the difference that financial constraints make to the inventory decisions of firms.

Table 4 presents correlations between variables in the simulated data. The main issue of interest here is to see how well the state variables (the random realizations of demand and cost)

\footnotetext{
${ }^{19}$ For the simulation sample, $N$ measures inventory change as the change in the number of units times the market price. Our results do not change if, in an attempt to mimic the LIFO method, we measure inventory at cost of production. When the change is positive (current production exceeds sales), we value the change at current period per unit production cost. If the change is negative (sales exceeds current production), we value the change at the previous period's per unit production cost.

${ }^{20}$ The exceptions occur for sales over capital and sales growth, and even here, the difference between constrained and unconstrained firms is minor.
} 
correlate with other firm variables that commonly feature in inventory studies. There are several noteworthy features.

The correlations reveal that a better state of cost is associated with higher sales over lagged capital, inventory growth and sales growth, higher investment scaled by lagged capital, cash flow scaled by lagged capital, and capacity utilization. Firms accumulate inventory when the cost shock is favorable, consistent with sales smoothing, and stock up for bad times. For the demand state, the correlations with inventory growth and inventory over capital are negative. This may appear contrary to intuition, given that the $\operatorname{ARMA}(1,1)$ structure has the property that after a positive shock, demand builds up quickly, and in anticipation, firms increase inventory. The reason for the negative correlation is that while inventory builds up after the initial positive demand shock, firms start selling from inventory very quickly while the demand state is still high, generating an overall negative correlation ${ }^{21}$ However, the negative correlation is weaker for financially constrained firms, consistent with the idea that they take longer time to build inventory, and also have an incentive to buffer inventory for adverse states. When we examine the correlations with the cost and demand shocks (which we define to be the negative of the change in the cost realization and the change in the demand realization, respectively), these are both positively correlated with sales growth and inventory growth.

The correlations among the remaining variables are consistent with expectations. One interesting set of comparisons between unconstrained and constrained firms involves capacity utilization. First, consistent with financially constrained behavior, constrained firms need to build capital much more rapidly when existing production capacity is being fully utilized than do unconstrained firms - the correlation between capacity utilization and capital growth is 0.66 for constrained firms but only 0.28 for unconstrained firms. In other words, unconstrained firms generally appear to

\footnotetext{
${ }^{21}$ The effect of lagged demand level $z_{t-1}$ decays at the speed of the persistence $\rho_{X}<1$ over time, but the effect of innovation decays at the speed of $\rho_{X}+\rho_{\varepsilon}$ first and then $\rho_{X}^{t-1}\left(\rho_{X}+\rho_{\varepsilon}\right)$. Therefore, correlation of lagged demand level and inventory is negative but the correlation of demand shock and inventory is positive in the short run if $\rho_{X}+\rho_{\varepsilon}>1$ and becomes negative afterwards.
} 
be closer to optimal capacity when they reach fuller utilization of capacity, but constrained firms need to expand capacity much more quickly. Second, when capacity is more fully utilized, unconstrained firms carry more inventory in relation to capital than do constrained firms: the correlation between capacity utilization and inventory-to-capital ratio is 0.84 for unconstrained firms compared to 0.66 for constrained firms. This suggests a need for the constrained firms of building up inventory when capacity is more fully utilized (in response to favorable shocks). Consistent with this, we find that the correlation of capacity utilization and inventory growth for unconstrained firms is 0.37 , compared to 0.58 for constrained firms.22

\section{Empirical Results from Actual and Simulated Samples}

\subsection{The Asymmetric Response on Model-generated Data}

Our purpose in this section is to first test whether the hypothesis of asymmetric response is valid in the model-simulated data. To do so, we regress model-generated inventory growth (change in inventory scaled by lagged capital) on the change in the level of the cost or demand realization scaled by its standard deviation (this is what we call a cost or demand "shock").

In our regression specification, in addition to the cost and demand shocks, we include an interaction of the shock with an indicator variable that takes a value of 1 if the firm is financially constrained in the model, and 0 if it is unconstrained. We consider favorable (positive, denoted with a plus sign) and unfavorable (negative, denoted with a minus sign) shocks separately ${ }^{23}$. To

\footnotetext{
${ }^{22}$ The correlations of sales growth with inventory growth, especially for unconstrained firms, are very high. While in the real data unconstrained firms also exhibit higher correlation of sales and inventory growth than do constrained firms, the magnitudes are much smaller. Two factors account for this difference. First, unconstrained firms are identical in our simulation panels, unlike real data where there is significant cross-sectional heterogeneity. Second, our assumption that unconstrained firms face no financing frictions is admittedly extreme and made for simplicity - allowing some degree of friction would make these firms more similar to constrained firms and would reduce the correlations. In regression results reported below, it will be seen that the higher correlations translate to regression coefficients when inventory growth is regressed on sales growth that are three times larger than those we get for the actual data. However, the focus of our analysis is to understand the asymmetric response of financially constrained firms vis-a-vis the unconstrained firms, which is preserved in the real data.

${ }^{23}$ Recall that a cost shock is the negative of a change in the level of the cost realization.
} 
control for expected shocks, in these regressions we also control for the lagged state, that is, the lagged value of the cost or demand realization.

The results reported in Panel A of Table 5 are supportive of the asymmetric response of inventory to cost and demand shocks in the short term. Both the positive and negative cost shock variables have significant positive coefficients, indicating that unconstrained firms add (deplete) inventory in response to of a positive (negative) cost shock. The interaction of the positive cost shock with the financial constraint dummy is negative, indicating that financially constrained firms respond more sluggishly to positive shocks; in contrast, the interaction of the negative cost shock with the dummy is positive, suggesting more aggressive inventory depletion. Note that we control for the lagged cost state (higher values represent more favorable state), which also has a positive coefficient. Since the lagged state predicts the expected magnitude of the shock, our results can be interpreted as firms' response to the unexpected component of the shock. We get very similar results for demand shocks, although the economic magnitude of the difference in the response of constrained and unconstrained firms to the demand shocks are not large.

In Panel B of Table 5, we examine the dynamics of inventory adjustment by the two types of firms in response to cost and demand shocks. We create indicator variables, 'Fav' and 'Adv', for extreme shocks in the previous periods. 'Fav' ('Adv') equals to 1 if the average cost or demand shocks over the past 6 periods is in the top (bottom) 20th percentile of the distribution, and 0 otherwise. We add these indicator variables and their interactions with the financial constraint dummy to our specification in Panel A. The interaction coefficients for the Fav dummies is significantly positive, while that for the $A d v$ dummies is significantly negative, for cost shocks. The uninteracted Fav and $A d v$ coefficients are also positive and negative, respectively. These results suggest that while unconstrained firms accumulate (reduce) inventory for several periods after favorable (unfavorable) cost shocks, financially constrained firms do so more aggressively. Thus, the asymmetry between the upside and the downside disappears in the longer term. For demand shocks, the behavior of the unconstrained firms is the opposite of that with cost shocks, as they 
sell from inventory after the initial favorable demand shock as demand surges. However, the financially constrained firms sell less. Conversely, after an extreme unfavorable demand shock, firms are left with excess inventory; however, the financially constrained firms reduce inventory more rapidly, as they run into operating losses.

We use the model as a laboratory to perform falsification tests to examine whether our results could possibly be driven by differences in other aspects except financing costs. We model two groups of firms with only one difference at a time: financially unconstrained firms in our baseline calibration, referred as benchmark firms, and firms with the same calibration but higher operating cost, higher investment adjustment cost, or lower production cost, respectively. The latter group of firms, referred as comparison firms, have higher inventory-to-capital ratios on average as shown in Table 2 so that they mimic financially constrained firms. However, these differences cannot generate the different inventory behaviors between those two groups of firms as we see between the financially constrained and unconstrained firms. The results are available on request.

\subsection{The Asymmetric Response on Actual Data}

We next examine the predictions of the model on real data. Since it is difficult to identify demand shocks in the real data, we focus on cost shocks ${ }^{24}$ Our first approach is to proxy the cost shocks with the annual intermediate input price changes at the industry level and test whether the asymmetric response of inventory growth to cost shocks can be obtained from the actual data.

Cost shocks can originate in shocks to prices of intermediate energy, materials, purchased service input, and labor compensation. Price indices for these components at the industry level at the annual frequency can be obtained from the Bureau of Economic Analysis.25 We take the

\footnotetext{
${ }^{24}$ In our model, cost shock contribute more to inventory growth even though we calibrate the parameters of the shock processes so that demand and cost shocks contribute equally to sales growth.

${ }^{25}$ According to BEA, the data are from GDP by Industry accounts released on November 5, 2015, as part of the annual revision to the industry economic accounts (IEAs). The data for 1947-1996 are from GDP by industries historical time-series released on February 19, 2016 and have been updated to be consistent with IEAs comprehensive revision. Statistics were prepared with methodologies that are unique to the GDP by Industry accounts and are
} 
percentage change in Chain-Type Price Index for intermediate inputs by industry as our measure for cost shocks. The price indices are available throughout our sample period from 1971 to 2010, and can be matched to firms by their NAICS ${ }^{26}$ To correspond with the frequency of the input price changes, we test our prediction with the annual Compustat data. For each firm-year observation, we define the (negative of) the industry input price change that occurred in the year prior to the firm's fiscal year-end date as the cost shock, 27 and perform the same regression as we did with the simulated data in Table 5. Our prediction is that while unconstrained firms accumulate (deplete) inventory in response to favorable (unfavorable) cost shocks, constrained firms react more sluggishly (aggressively).

We use an almost identical specification as our regression with simulated data in Section 4.1. Cost shock is again split into favorable and unfavorable shocks, and each is interacted with a financial constraint dummy. As discussed previously, we use four commonly used financial constraint classifications. We define the favorable (unfavorable) shocks as input price reductions that are above (below) the industry's median reduction ${ }^{28}$ As in our baseline model with the real data, we control for the financial constraint dummy, the lagged value of inventory over lagged capital, capital growth, lagged cash flow, and its interaction with the financial constraint dummy. We also incorporate firm fixed effects and year fixed effects to control for the unobserved time-varying shocks common to all firms and the unobserved heterogeneity at the firm-level.

The results, reported in Table 6, show that the asymmetric response is evident for each of the financial constraint measures. Constrained firms respond to favorable shocks more sluggishly and even deplete inventory (our model suggests that they do so to save internal funds for capacity for industries defined according to the 2007 North American Industry Classification System (NAICS).

${ }^{26}$ The Chain-type price index is prepared using the single-deflation method. An industry's current-dollar value added statistics are divided by the industry's gross output price index. The results approximate that obtained by double deflation when the prices of an industry's intermediate inputs increases at about the same rate as its output prices. For more information, see Yuskavage (2002).

${ }^{27}$ We multiply the input price change by minus one to be consistent with our notion that positive (negative) movements are associated with favorable (unfavorable) cost shocks.

${ }^{28}$ Our results are very similar if we define the favorable (unfavorable) shocks as industry-year with positive (negative) input price reduction. 
expansion as they expect the favorable shock to persist). However, when the cost shocks turn adverse, they cut down on inventory holdings and do so much more aggressively than the unconstrained firms. Somewhat surprisingly, the latter firms accumulate more inventory when the adverse shocks become worse. Since these shocks are industry-wide shocks, it is possible that the unconstrained firms accumulate inventory in the expectation that the constrained firms in the same industry will run out of inventory and would have to cut sales.

\section{Input Price Changes at Quarterly Frequency and In- strumented Sales Growth}

Our tests in Section 4 were based on input price changes at annual frequency at the industry level. To test the dynamics of inventory adjustment in response to cost shocks, we need data on input price changes at higher frequency. Unfortunately, quarterly price indices from BEA are available (at the sector level) only from 2005. In view of this data limitation, we rely on model predictions regarding (i) the relation between cost and demand shocks and sales growth (defined as change in sales over capital), and (ii) the relation between inventory growth and sales growth for financially unconstrained and constrained firms. In particular, we show in Section 5.1 below that our model implies that sales growth is positively associated with favorable cost and demand shocks, and that inventory growth of financially unconstrained and constrained firms responds to sales growth in the same way as it does to each of these shocks.

For our empirical tests, we appeal to these results to instrument sales growth of both financially unconstrained and constrained firms with quarterly change in commodity prices (available at monthly frequency). We also construct indices of industry-level input price changes based on Input-Output tables and producer price indices. Instrumenting sales growth allows us to identify more clearly the set of firms that are exposed, directly or indirectly, to commodity price changes or 
input price changes at the industry level. As we discuss below, firms may hedge their exposure to cost shocks, so that even within the same industry, they may have different exposure to cost shocks. We then test the model predictions based on the response of inventory growth to instrumented sales growth.

\subsection{Sales Growth as a Proxy for Cost and Demand Shocks}

We first demonstrate the relationship between cost and demand shocks and sales growth in our model, and the response of inventory growth to sales growth.

In the first two columns of Table 7, we regress sales growth (change in sales scaled by lagged capital) on standardized cost and demand shocks. Consistent with our expectation, both cost and demand shocks are significantly and positively related to sales growth. In Columns (1) and (2) where the shocks and their interactions with the financial constraint dummy are included, the regression $R^{2}$ is high - about 18 percent and 19 percent, respectively 29 The interaction of the cost shock with the financial constraint dummy is insignificant, and the economic magnitude is very small relative to that of the uninteracted term. The interaction of the demand shock with the financial constraint dummy is statistically significant, but the economic magnitude is also much smaller than that of the uninteracted term. These results suggest that in regressions in which sales growth is proxy for demand and cost shocks, it is unlikely that differences in the coefficients of sales growth for constrained and unconstrained firms are driven by differences in the sensitivity of sales growth to the underlying shocks.

Column (3) of reports the regressions of inventory growth on sales growth. The dependent variable is the change in inventory scaled by lagged capital. Similar to the cost and demand shock results reported earlier, sales growth is split into positive and negative growth, and each is interacted with a financial constraint dummy. We control for the financial constraint dummy, and

\footnotetext{
${ }^{29}$ The regression $R^{2}$ is about 36 percent when both shocks and their interactions are included at the same time.
} 
the lagged value of inventory over lagged capital. We also include a dummy variable, Adv, and its interaction with the financial constraint dummy. Adv takes a value of 1 if the firm's lagged sales growth is below the 20th percentile, and zero otherwise. The motivation is to see whether firms in our model, especially financially constrained ones, deplete more inventory when the shock is extremely adverse ${ }^{30}$ Moreover, we control for lagged cash flow, which has the highest correlation with the demand and cost realizations among all other financial variables in Table 4, to control for expected shocks to sales. The regression of inventory growth on sales growth and its interactions with the financial constraint dummy are consistent with those we observed when the cost and demand shocks were directly included.

We also find consistent results for the $A d v$ dummy. Both the dummy and its interaction are significantly negative, and the coefficient estimate on the interaction term is quite large. Firms deplete inventory more rapidly when the sales shock is very adverse, and constrained firms do so more aggressively.

Column (4) in Table 7 report results on the dynamic response of inventory to sales growth. We focus on extreme shocks. Indicator variable $A d v_{t-1, t-6}$ takes the value of 1 if the firm's average sales growth over the last six periods is below the 20th percentile of the firm-specific distribution of the rolling six-year average sales growth, and zero otherwise; indicator variable $F a v_{t-1, t-6}$ takes the value of 1 if the firm's average sales growth over the last six periods is above the 80th percentile, and zero otherwise. To contrast the dynamic response of the two types of firms, we focus on the interactions of these two variables with the financial constraint dummy. Consistent with a symmetric and more aggressive response to both positive and negative extreme sales shocks, the coefficients of the $\mathrm{Fav}_{t-1, t-6}$ and $A d v_{t-1, t-6}$ interacted with the financial constraint dummy are, respectively, positive and negative. This suggests that over a longer horizon following extreme shocks, financially constrained firms accumulate more inventory when the shocks are positive, and

\footnotetext{
${ }^{30} A d v$ and its interaction with the financial constraint dummy are important as benchmarks for the regressions with the real data.
} 
deplete more inventory when those are negative, than their unconstrained counterparts.

\subsection{Results Based on Quarterly Input Price Changes}

\subsubsection{Commodity Prices}

We focus on three commodities - oil, gold and silver. To identify which types of firms are directly or indirectly affected by changes in the prices of these commodities, we first regress, for each of industry, firms' quarterly sales growth on the quarterly price change of the commodity in question, and only keep those industries for which there is a significant positive relationship. We find significant effect of commodity price changes on sales growth only at a lag of two quarters for all three commodities ${ }^{31}$ Accordingly, we instrument sales growth by the commodity price change at a lag of two quarters.

Panel A of Table 8 reports the results for oil prices - results for gold and silver are similar and are available in the Internet Appendix. The regressions were run separately for each quarter to adjust for seasonality and then averaged over the four quarters, with the t-statistics calculated using the Fama-Macbeth method. We present our results for all four financial measures. The first four columns report the short-term response of inventory to predicted sales, and the last four report the dynamic response. Consistent with our earlier results, financially constrained firms increase inventory more sluggishly in response to higher positive predicted sales growth than their unconstrained counterparts. For negative predicted but moderate sales shocks, we do not find any evidence that firms are cutting back on inventory when sales drop, or that the constrained firms are cutting inventory more aggressively ${ }^{32}$ However, for extreme adverse shocks, both groups of firms cut back on inventory, and the constrained firms do so much more aggressively than do the

\footnotetext{
${ }^{31}$ As discussed below, this is also the case for our measure of quarterly input price changes at the industry level. It is possible that within a one-year period, firms are affected by past commodity or input price changes at different lags, with a majority affected at a lag of two quarters. We find that annual sales responds positively to one-year lagged annual input price change in virtually every industry.

${ }^{32}$ The coefficient of the interaction of the financial constraint dummy and predicted negative sales growth has the wrong sign in all four columns, although it is significant in only one column.
} 
unconstrained firms.

The last four columns present the evidence on the dynamic response of inventory to extreme favorable and unfavorable shocks. Financially constrained firms accumulate (deplete) more inventory when the predicted sales growth over the previous six quarters is extremely favorable (unfavorable), compared to financially unconstrained firms. In other words, the asymmetry between the upside and downside response vis-a-vis the unconstrained firms disappears over the longer horizon and the financially constrained firms appear to engage in more aggressive buffering behavior - accumulating more inventory when input costs are especially low (and profits are high) and depleting accumulated inventory when costs are especially high (and profits are low)

\subsubsection{Industry-level Input Prices}

Using Input-Output Tables and Producer Price indices available at quarterly frequency, we create a weighted measure of the relevant input price for all supplier industries based on the output prices of the industries they purchase products from. This measure is presumably noisier than the shorter time series available from BEA; however, the two indices are strongly positively correlated over the time period for which the latter is available. As with oil price changes, the input price change has a positive and significant coefficient on sales growth in a majority of industries when we lag the input price change by two quarters. Panel B of Table 8 presents the results when we instrument sales growth with industry-level change in input price lagged by two quarters. The results are similar to those in Panel A.

\section{Evidence from Quasi-Natural Experiment}

Since firm characteristics such as firm size that determine whether a firm is classified as financially constrained/unconstrained could directly affect inventory behavior (and not only via the financial constraint channel), we now examine inventory behavior around an event that provided exogenous 
variation to the degree of financial constraint faced by a group of firms. Lemmon and Roberts (2010) show that three near-concurrent events in 1989 (the Collapse of Drexel Burnham Lambert, Inc., the passage of the Financial Institutions Reform, Recovery, and Enforcement Act of 1989 (FIRREA), and a change in the National Association of Insurance Companies (NAIC) credit rating guidelines) led to a major contract of the availability of external finance for below-investment-grade firms. To understand how an exogenous change in financing constraint affects inventory investment compared to firms that are not exposed to such a change, in a difference-in-difference setting, we compare the inventory investment behavior for a set of below-investment-grade firms before and after the credit shock with that of matched unrated firms. We do this test for two sets of firms: (i) those that are exposed to a favorable (below industry time-series median) annual input price change for the three years before the credit shock as well as the three years after, and (ii) those that are exposed to an unfavorable annual input price change.

In this setting, we are able to examine the inventory adjustments of the firms that are hit by the credit shock and the matched firms both in the short and the longer run. Our short-run and long-run windows are the last three quarters of 1990 and the period from 1990Q2 to 1993Q4, respectively. Note that, since our classification of firms as exposed to favorable and unfavorable shocks involves three-year averages of the industry-specific input price change before and after the credit shock, if the inventory behavior of the firms affected by the credit shock and the matched unaffected firms become more similar in the longer term, this cannot be attributed to the effect of the cost shocks becoming weaker over time.

Following Lemmon and Roberts (2010), we also use the location of firms' headquarters as an instrument for the extent to which firms were affected by the shock. During the 1990-91 period, banks in the northeastern part of the United States had difficulty meeting minimum capital requirements, and sharply contracted lending ${ }^{33}$ Earlier studies (Bernanke and Lown, 1991 and

\footnotetext{
${ }^{33}$ The northeastern part consists of the New England region including Maine, New Hampshire, Vermont, Massachusetts, Rhode Island, Connecticut, and the Mid-Atlantic region including New York, New Jersey, and Pennsylvania.
} 
Peek and Rosengren, 2008, among others) have identified the collapse of the New England and MidAtlantic real estate bubbles as the most important driving force behind the contraction in bank lending. If bank lending is cut back, bank-dependent firms in the affected region may find it more costly to obtain credit. In addition, the contemporaneous credit shock to the below-investmentgrade firms, discussed above, made it very difficult for these firms to substitute away from bank to nonbank credit. Therefore, the credit shock provides us an event that increased the external financing cost but, as we validate below, is likely exogenous to the investment opportunities of bank-dependent firms in the Northeast region.

The full sample for the two tests consists of all the unrated firms and firms with a belowinvestment-grade debt rating $(\mathrm{BB}+$ or lower) in the quarterly Compustat database during the period 1986 to 1993 with the same restrictions as in our main sample. The location information, which is obtained from Bill McDonald's website, is based on headers for 10-K forms from 1994 to 2010. Since our entire sample period for this exercise is immediately prior to 1994, we use the 1994 location information.

For both our difference-in-difference tests, we define the period from 1986Q1 to 1989Q4 as the window before the shock, and the period from 1990Q2 to 1993Q4 as the window after the shock. Moreover, as mentioned above, we consider the first three quarters after the shock (1990Q2 to 1990Q4) to be the short-run window in order to study the immediate response after the shock. Indicator variable After dummy takes a value of one for the quarters 1990Q2 to 1990Q4 (1990Q2 to 1993Q4) for the short-run (long-run) window, and zero for 1986Q1 to 1989Q4. Following Lemmon and Roberts (2010), we require that we have at least one observation in both the before and the after period for each firm, and require that firms do not change between the treatment and control groups in the sample period.

Our empirical strategy is to test whether an increase in the degree of financial constraint changed the affected firms' inventory investment behavior, compared to firms that were not affected 
by the financial constraint shock, in a manner consistent with the theory developed in the paper. We expect that the way in which inventory investment of the treated (newly constrained) firms is affected depends on whether the firms are in good or bad cost shock states. In particular, we expect that when the cost shock is favorable, in the short window after the capital crunch, the treated firms exposed to favorable cost shocks will accumulate inventory more slowly than the control firms, and the difference will become less pronounced in the longer window. When the cost shock is unfavorable, the treated firms deplete inventory more aggressively in the shorter window, and the difference between the treated and control firms' inventory behavior will become more pronounced over the longer window.

Our empirical results are mostly in line with these predictions. Panel A of Table 9 presents results for the first difference-in-difference test, in which the treated firms are below-investment grade firms and the control firms are the industry-and-size-matched unrated firms. Following Lemmon and Roberts (2010), we only keep those treated firms that do not change ratings between 1986 and $19933^{34}$ The regressions are reported separately for firms experiencing favorable and unfavorable cost shocks and for both the short-run and long-run. Consistent with the model, when the cost shock is favorable, the interaction of BelowInvestment and After is significantly negative in the short window, but becomes smaller in magnitude over the longer window. When the cost shock is unfavorable, as expected, the interaction is negative (though insignificant) over the shorter window, and becomes statistically significant over the longer window. Note also that the dummy variable Preshock which takes a value of 1 for the three quarters before the shock is insignificant, and the interaction of Preshock and BelowInvestment is also insignificant,

\footnotetext{
${ }^{34}$ One consequence of this is that our sample size is modest - especially for those exposed to unfavorable shocks. A firm belongs to the "favorable cost shock" group if the three year average annual input price change for its industry is below the time series median for the industry. However, following the same definition for classifying firms exposed to unfavorable shocks leaves us with a very small number of firms and industries. Accordingly, we relax the requirement for the post 1990 period by only requiring that the three-year average input price change not be "extremely favorable" - defined as being above the 80th percentile of the time-series distribution for the industry. Note that since we hypothesize that the treated firms will cut down on inventory investment in the postcapital crunch period when subjected to adverse cost shocks, such a relaxation of the requirement biases against our expected results.
} 
confirming that differences in pre-tends do not drive our results.

We find more-or-less similar but somewhat stronger results in Panel B, where we report the results for our second difference-in-difference test. The treated firms are below investment grade and unrated firms located in the Northeast ${ }^{35}$ The control firms are the industry-and-size-matched firms located elsewhere in the country and does not differ from the treated group before the shock except for the location of headquarters. If the choice of headquarters is exogenous to the investment opportunities, by exploiting the variation in the geographic location of firms, we are able to identify the impact of financial constraints. For favorable cost shocks, the coefficients of the interaction between the After dummy and the Northeast dummy is significantly negative in the short window and insignificant over the longer window. On the other hand, when for unfavorable cost shocks, the interaction is insignificant in the short run, but becomes significantly negative in the longer run. For the subsample of firms experiencing unfavorable shocks, while the dummy variable Preshock has a significant negative coefficient ${ }^{36}$, the interaction of Preshock and Northeast is insignificant, confirming that differences in trends do not drive our results.

We also verify that the financial shock did not affect growth potential of the treated and control firms differently, which could be a possible alternative explanation for the divergent inventory investment behavior. For both tests, the average sales growth of the treated and control firms conditional on their cost state is not different before and after the shock. Table IA.2 in the Internet Appendix reports regression results in an identical difference-in-difference framework to those in Table 9 in which the dependent variable is firm sales growth. The interaction of After and BelowInvestment (resp., of After and Northeast), is insignificant.

\footnotetext{
${ }^{35}$ Here, we do not impose the requirement that the treated firms do not change rating status during 1986-1993, since the additional restriction on location for the treated firms would further reduce sample size. Consequently, we retain a larger number of treated firms.

${ }^{36} \mathrm{It}$ is possible that the treated group in Panel B experiencing unfavorable shocks identifies industries that were more exposed to the sluggish growth in the economy during the previous three quarters.
} 


\section{Allowing Firms to Hedge}

Froot, Scharfstein and Stein (1993) argue that when the payoff function for firms is concave in investment, financially constrained firms that rely on internal funds for investment have an incentive to hedge cash flows. Adam, Dasgupta and Titman (2007) extend this framework to study hedging choices of financially constrained firms in industry equilibrium. They show that the flexibility of producing more (less) when costs are low (high) makes a firm's profit function convex in investment, and creates an incentive for firms not to hedge cash flows. They show that, in industry equilibrium, some firms will hedge cash flows, and others will not.

Important for the analysis of Adam, Dasgupta and Titman (2007) is the well-known result that a price-taking firm's profit function is convex in the (linear) marginal cost of production. Ceteris paribus, a price-taking firm prefers facing a random marginal cost to a constant marginal cost of the same expected value because it then has the option of producing a higher output when cost is low, and cutting back on output when cost is high. A similar motivation drives production cost-smoothing behavior in our model - however, our model allows firms to take even greater advantage of this flexibility by carrying inventory from low-cost states to high-cost states. This is primarily the incentive that drives the inventory behavior of unconstrained firms. However, since we deviate from the model of price-taking firms and also have capital adjustment costs, it is not ex ante clear whether unconstrained firms would be better off if they could hedge their exposure to cost shocks.

A similar argument applies to constrained firms as well, although here the interactions are more complex. On the one hand, remaining unhedged allows these firms to increase cash flows and expand their capacity and production in those states in which it is profitable to produce ${ }^{37}$ On the other hand, since they may have to engage in costly asset sales when they incur operating losses in bad states, they may prefer to avoid exposure to extreme shocks and reduce liquidity risk.

\footnotetext{
${ }^{37}$ Note that Froot, Scharfstein and Stein (1993) assume that firm's investment opportunities are uncorrelated with cash flows. However, if the correlation was positive, firms would prefer to remain unhedged.
} 
In our model, they mitigate the latter by using inventory accumulated in the good cost states as a liquidity buffer. However, again, whether they are better off hedging input cost shocks is an empirical question.

How do these considerations affect our results? We discuss this next.

\subsection{Hedging Input Price Shocks}

Hedging reduces the volatility of shocks, and could leave the financially constrained firms more or less exposed to these shocks than their unconstrained counterparts. We can use our model to examine how sensitive the differences in inventory behavior between financially constrained and unconstrained firms are to the differences in the volatility of the shocks faced by these two types of firms. Since we do not have a prior on which type of firms face more volatile shocks ex post, we experiment with a wide range of scenarios, under which the volatility of cost shock for financially constrained firms relative to that for unconstrained firms is $0.5,0.75,0.875,1.125,1.25$, or 1.5 , respectively. We solve the model and run the baseline tests using the simulated data under each of these scenarios. As shown in Table IA.3 in the Internet Appendix, the average inventory-tocapital ratio of financially constrained firms is higher than that of unconstrained firms under all six scenarios. More importantly, the main result of the paper still holds under each of these scenarios: financially constrained firms increase inventory more sluggishly under favorable cost shock and deplete inventory more aggressively under unfavorable cost shock. Finally and not surprisingly, the differences in the sensitivity of the inventory response by unconstrained firms vis-a-vis the constrained firms to cost shocks during both good and bad states are larger in absolute value when constrained firms are less able to hedge cost shocks. Thus, the results of this experiment suggest that the differences in inventory behavior between financially constrained and unconstrained firms are fairly robust to the differences in the ex post volatility of the shocks faced by these two types of firms. 
Next, we examine whether and how the response of inventory investment to annual industrylevel input price changes are affected by the possibility of hedging input price shock. We classify industries as "high hedging" based on the potential usage of purchase obligations to hedge input price fluctuations. Almeida, Hankins and Williams (2017) (hereinafter AHW) argue that derivatives are mainly used by financially unconstrained firms due to its requirement for collateral. They show that purchase obligation is a risk management tool available to both financially constrained and unconstrained firms and is widely used. A firm's usage of purchase obligations to hedge input price variations depends on its supplier's bargaining power and settlement risk. Following AHW, we measure supplier bargaining power in terms of the supplier industry Herfindahl-Hirschman Index, and weigh the index of each supplier industry by the importance of the supplier industry to the customer industry to arrive at a proxy for supplier bargaining power for each customer industry. AHW also show that supplier Z-score proxies for supplier settlement risk and has a significant positive impact on the amount of purchase obligations used by firms. We calculate the median Z-score for each industry, and for each customer industry, calculate the weighted Z-score of all supplier industries. Based on the above two measures, we consider those industries with below-mean value of supplier industry HHI (above-mean value of supplier industry Z-score) as "high hedging" industries 38

Our results (reported in the Table IA.4 in the Internet Appendix) show that for the highhedging industries, the sensitivity of inventory investment to favorable shocks disappears for unconstrained firms, and the sensitivity to unfavorable shocks is weaker when supplier settlement risk is low. However, our earlier results that constrained firms adjust inventory more sluggishly (more aggressively) than their unconstrained counterparts when cost shocks are favorable (unfavorable) remain even in the high hedging industries.

\footnotetext{
${ }^{38}$ Based on hand-collected data on derivative hedging of S\&P 500 firms, Disatnik, Duchin and Schmidt (2014) provide a classification of industries on the basis of hedging intensity. Since smaller financially constrained firms are unlikely to rely on derivative hedging, we do not base our tests on this measure.
} 


\subsection{Cash Holding and Inventory Behavior}

If holding cash were costless, the inventory behavior of financially constrained and unconstrained firms would be identical. Essentially, by buffering enough cash, constrained firms would become unconstrained. Thus, the entire literature on financially constrained behavior implicitly assumes that there is a cost to holding cash 39 For our purposes, the issue is whether the cost of carry is high enough that differences in inventory holding behavior are likely to remain between financially constrained firms and unconstrained firms. Due to the "curse of dimensionality", our numerical solution technique cannot handle solving the optimal cash holding problem together with solving for optimal inventory, output, and investment. Moreover, estimates of the cost of carry are difficult to obtain. Therefore, we try to address this issue indirectly.

We take two approaches. First, we examine whether the differences in the downside sensitivities remains even when the median industry cash holding is high. To this end, in Column (1) (Column (2)) of Table IA.5 in the Internet Appendix, we create a dummy variable Lcash which takes the value of 1 when the median cash holding in the industry is below the median of the time series (cross-sectional) distribution, and zero otherwise. We examine whether, when cash holding is high, the difference in the sensitivity of the inventory investment to adverse cost shock is still significantly higher for financially constrained firms compared to unconstrained firms. The interaction of the adverse shock and the financial constraint dummy (that is, the term that corresponds to the high cash holding state) remains significant in both columns. In other words, the cost of carry of cash is high enough that, even when financially constrained firms are carrying a high level of cash holding to these adverse states, they are not carrying "enough cash" to obviate the need of an

\footnotetext{
${ }^{39}$ Holding "cash" in the form of interest-bearing assets such as treasury bills is costly because interest on cash holdings is taxed (Riddick and Whited (2009)), and shareholders get less than the appropriate risk-adjusted return. Shareholders are better off if the firm uses the cash to repurchase shares rather than hold it in the form of an interest-bearing asset the income from which is taxed twice. If the cash is held in the form of currency or non-interest-bearing deposits, the value of this cash erodes in an inflationary environment, and inventory offers a better hedge against inflation (this would be the case in our model if the cost shocks are correlated across firms). Finally, we could assume that shareholders prefer managers to pay out cash and hold an inventory buffer instead since managers can deviate from the pursuit of shareholder value maximizing policies when private benefit-laden projects are present. This "free cash flow" problem could be the most significant cost of cash holding.
} 
inventory buffer: they rely on offloading inventory more aggressively than their unconstrained counterparts when hit with adverse shocks. The triple-interaction including the Lcash dummy is also significantly positive. This shows that, consistent with our expectation, constrained firms deplete inventory less aggressively when firms in the industry have high cash holdings than when they have low cash holding. Finally, whether cash holding is high or low also has no effect on the downside sensitivity of the unconstrained firms in Column (1), as expected (although it has a positive effect significant at the $10 \%$ level in Column (2)).

We also conduct a simulation exercise in which cash drawdowns are modelled as negative dividends scaled by capital. We determine the amount of (maximum permitted) drawdown for which short-and-long run sensitivities between financially constrained and unconstrained firms disappear, and compare these thresholds to the actual distribution of cash drawdowns in the real data (which implicitly reflect the limits imposed by the firms' cash holding position). Figure IA.1 in the Internet Appendix shows that while the long-run difference in sensitivity to favorable cost shocks (in other words, the more prolonged buffering behavior by constrained firms in response to favorable shocks) disappears around the 79 percentile, the other sensitivities survive until extreme percentiles of the drawdown distribution (93, 98, and 99 percentiles for short run sensitivity of favorable cost shocks, long run sensitivity of favorable cost shocks, and short run sensitivity of unfavorable cost shocks, respectively). Overall, these results suggest that the cost of carry associated with cash holding is likely high enough that the observed differences in behavior are unlikely to disappear in our model if firms were permitted to hold cash.

\section{Conclusion}

Changes to firms' inventory holdings have long been regarded as an important component of business fluctuations, as has the propagation of monetary policy shocks to the real economy via firms' access to finance. While earlier empirical attempts either found little relationship between 
the cost of finance and inventory holding behavior, more recent evidence suggests that monetary policy may have important effects on the inventory holding behavior of firms that have difficulty in accessing external finance. There has been little attempt, however, to link the effect of financial constraints to inventory policy theoretically.

In this paper, we develop a theoretical model that studies the interaction of financial constraints and inventory behavior. The main intuition we try to model is that firms' incentives to build inventory when costs are low (and demand is high), and deplete inventory when costs are high (demand is low) are exacerbated when they face financial constraints and have difficulty in rebuilding capital. The model provides a number of insights on the determinants of inventory holdings in the presence of financial constraints. Using model-generated data, we develop several empirical tests of the theory. These tests have the advantage that we do not need to interpret coefficients of cash flows in our regressions, which has been controversial due to measurement error issues. When we take these tests to the actual data, we find consistent results. 


\section{References}

Adam, Tim, Sudipto Dasgupta and Sheridan Titman. 2007. "Financial Constraints, Competition, and Hedging in Industry Equilibrium." The Journal of Finance 62(5):2445-2473.

Almeida, Heitor, Kristine Hankins and Ryan Williams. 2017. "Risk Management with Supply Contracts." Working paper.

Altig, David, Lawrence Christiano, Martin Eichenbaum and Jesper Linde. 2011. "Firm-Specific Capital, Nominal Rigidities and the Business Cycle." Review of Economic Dynamics 14(2):225247.

Aruoba, S. Boragan, Jesus Fernandez-Villaverde and Rubio-Ramirez Juan F. 2006. "Comparing solution methods for dynamic equilibrium economies." Journal of Economic Dynamics \& Control 30:2477-2508.

Belo, Frederico and Xiaoji Lin. 2012. "The Inventory Growth Spread." Review of Financial Studies 25(1):278-313.

Belo, Frederico, Xiaoji Lin and Fan Yang. 2016. "External Equity Fianncing Shocks, Financial Flows, and Asset Prices." Working paper of University of Minnesota, Carlson School of Management.

Bernanke, Ben S and Cara S Lown. 1991. "The Credit Crunch." Brookings Papers on Economic Activity 1991(2):205.

Blanchard, Oliver J. 1983. "The Production and Inventory Behavior of the American Automobile Industry." Journal of Political Economy 91(3):365-400.

Blinder, Alan S. 1981. "Retail Inventory Behavior and Business Fluctuations." Brookings Papers on Economic Activity 2:443-520.

Blinder, Alan S. 1986. "Can the Production Smoothing Model of Inventory Behavior be Saved?" The Quarterly Journal of Economics 101(3):431-454.

Blinder, Alan S. and Louis J. Maccini. 1991. "The Resurgence of Inventory Research: What Have We Learned?" Journal of Economic Surveys 5(4):291-328.

Bruno, Michael and Jeffrey Sachs. 1982. "Input Price Shocks and the Slowdown in Economic Growth: The Case of U.K. Manufacturing." The Review of Economic Studies 49(5):679.

Carpenter, Robert E., Steven M. Fazzari and Bruce C. Petersen. 1994. "Inventory Investment, Internal-Finance Fluctuations, and the Business Cycle." Brookings Papers on Economic Activity $2: 75-138$.

Carpenter, Robert E., Steven M. Fazzari and Bruce C. Petersen. 1998. "Financing Constraints And Inventory Investment: A Comparative Study With High-Frequency Panel Data." The Review of Economics and Statistics 80(4):513-519. 
Disatnik, D, R Duchin and B Schmidt. 2014. "Cash Flow Hedging and Liquidity Choices." Review of Finance 18(2):715-748.

Durlauf, S. and L. Maccini. 1995. "Measuring Noise in Inventory Models." Journal of Monetary Economics 36(1):65-89.

Eichenbaum, Martin. 1989. "Some Empirical Evidence on The Production Level and Production Cost Smoothing Models of Inventory Investment." American Economic Review 79(4):853-864.

Froot, Kenneth A., David S. Scharfstein and Jeremy C. Stein. 1993. "Risk Management: Coordinating Corporate Investment and Financing Policies." Journal of Finance 48:1629-1658.

Gomes, Joao F., Amir Yaron and Lu Zhang. 2003. "Asset Prices and Business Cycles with Costly External Finances." Review of Economic Dynamics 6(4):767-788.

Hadlock, C J and J R Pierce. 2010. "New Evidence on Measuring Financial Constraints: Moving Beyond the KZ Index." Review of Financial Studies 23(5):1909-1940.

Hennessy, Christopher and Toni Whited. 2007. "How Costly is External Financing? Evidence from a Structural Estimation." Journal of Finance 62:1705-1745.

Imrohoroglu, Ayse and Selale Tuzel. 2014. "Firm Level Productivity, Risk, and Return." Management Science 60(8):2073-2090.

Jones, Christopher S. and Selale Tuzel. 2013. "Inventory Investment and the Cost of Capital." Journal of Financial Economics 107(3):557-579.

Kashyap, Anil K., Jeremy C. Stein and David W. Wilcox. 1993. "Monetary Policy and Credit Conditions: Evidence from the Composition of External Finance." American Economic Review 83(1):78-98.

Kashyap, Anil K., Owen Lamont and Jeremy C. Stein. 1994. "Credit Conditions and the Cyclical Behavior of Inventories." The Quarterly Journal of Economics 109(3):565-92.

Lemmon, Michael and Michael R. Roberts. 2010. "The Response of Corporate Financing and Investment to Changes in the Supply of Credit." Journal of Financial and Quantitative Analysis $45(3): 555-587$.

Peek, Joe and Eric Rosengren. 2008. "The Capital Crunch: Neither a Borrower nor a Lender Be." Journal Of Money, Credit and Banking (Ohio State University Press) 27:625-638.

Ramey, Valerie Ann. 1989. "Inventories as Factors of Production and Economic Fluctuations." American Economic Review 79(3):338-354.

Ramey, Valerie Ann and Kenney D. West. 1999. Inventories. In Handbook of Macroeconomics, ed. J. B. Taylor and M. Woodford. 1 ed. Vol. 1 Elsevier chapter 13, pp. 863-923. 
Riddick, Leigh and Toni Whited. 2009. "The Corporate Propensity to Save." Journal of Finance 64:1729-1766.

Salinger, Michael and Lawrence H. Summers. 1983. Tax Reform and Corporate Investment: A Microeconometric Simulation Study. National Bureau of Economic Research, Inc. pp. 247-288.

Wang, Pengfei and Yi Wen. 2011. "Inventory Accelerator in General Equilibrium." Manuscript, Hong Kong University of Science and Technology and Federal Reserve Bank of St. Louis.

West, Kenneth. 1986. "A Variance Bounds Test of the Linear Quadratic Inventory Model." Journal of Political Economy 94(2):374-401.

Whited, Toni and Guojun Wu. 2006. "Financial Constraints Risk." Review of Financial Studies 19:531-559.

Yuskavage, Robert E. 2002. "Gross Domestic Product by Industry: A progress report on accelerated estimates." Survey of Current Business 82(6):19-27. 


\section{Appendices}

\section{A Solution Method}

Since the productivity level has a constant growth trend $A_{t}=g^{t}$, we need to show that the model has a solution on the balanced growth path where all the variables growth at a constant rate. We first guess that firm value $V_{t}$, capital level $K_{t}$, sales $S_{t}$, inventory $N_{t}$, the costs $C_{Q t}, C_{O t}$, and $C_{I t}$, and dividend $D_{t}$ all grow at the same rate as $A_{t}$. Define the scaled variables as follows:

$$
\begin{gathered}
\tilde{K}_{t}=\frac{K_{t}}{A_{t}} \quad \tilde{I}_{t}=\frac{I_{t}}{A_{t}} \quad \tilde{D}_{t}=\frac{D_{t}}{A_{t}} \quad \tilde{C}_{Q, t}=\frac{C_{Q, t}}{A_{t}} \quad \tilde{C}_{N, t}=\frac{C_{N, t}}{A_{t}} \quad \tilde{C}_{I, t}=\frac{C_{I, t}}{A_{t}} \quad \tilde{C}_{O, t}=\frac{C_{O, t}}{A_{t}} \\
\tilde{V}_{t}=\frac{V_{t}}{A_{t}} \quad \tilde{Q}_{t}=\frac{Q_{t}}{A_{t}} \quad \tilde{S}_{t}=\frac{S_{t}}{A_{t}} \quad \tilde{N}_{t}=\frac{N_{t}}{A_{t}} .
\end{gathered}
$$

In what follows, we rewrite the first order conditions of the model in terms of the scaled variables. It then becomes clear that the first order conditions do not depend on time $t$. That is, the solution of the scaled variables is stationary and their corresponding variables are indeed growing at the constant rate of $g$.

Our solution method is the second-order perturbation method, which requires that the objective function is differentiable and unconstrained. A.1 For constrained firm, the optimization problem can be approximated by the following

$$
\hat{V}_{t}\left(K_{t-1}, N_{t-1}, X_{t}, Z_{t}\right)=\max _{\left\{Q_{t}, N_{t}, I_{t}\right\}}\left\{D_{t}+\beta \mathbb{E}_{t}\left[\hat{V}_{t+1}\right]+\left(\frac{A_{t}}{\varpi_{1}}\right) \log \left(\frac{D_{t}}{A_{t}}\right)\right\},
$$

where the last term drops to negative infinity rapidly as $D_{t}$ is close to zero and is called logarithmic barrier. As $\varpi_{1}$ increases to $\infty$, the above optimization problem converges to our original optimization problem. In our calibration, we increase $\varpi_{1}$ gradually until the model solution converges. To add the constraints that output cannot exceed the capacity, we follow the same strategy, i.e.,

$$
\begin{aligned}
\hat{V}_{t}\left(K_{t-1}, N_{t-1}, X_{t}, Z_{t}\right)= & \max _{\left\{Q_{t}, N_{t}, I_{t}\right\}}\left\{D_{t}+\beta \mathbb{E}_{t}\left[\hat{V}_{t+1}\right]\right. \\
& \left.+\left(\frac{A_{t}}{\varpi_{1}}\right) \log \left(\frac{D_{t}}{A_{t}}\right)+\left(\frac{A_{t}}{\varpi_{2}}\right) \log \left[A_{0}\left(\frac{K_{t-1}}{A_{t}}\right)^{\alpha}-\left(\frac{Q_{t}}{A_{t}}\right)\right]\right\},
\end{aligned}
$$

where the last term is the logarithmic barrier for the output constraint and the value of $\varpi_{2}$ is chosen similarly as that of $\varpi_{1}$.

For financially constrained firms, the first order conditions w.r.t. $\tilde{N}_{t}, \tilde{Q}_{t}$ and $\tilde{I}_{t}$ using scaled

\footnotetext{
A.1The value function iteration method is not subjected to this constraint however it suffers from the curse of dimensionality. Given that our model has four state variable $\left(\left\{K_{t-1}, N_{t-1}, X_{t}, Z_{t}\right\}\right.$ and three independent endogenous variables $\left\{Q_{t}, N_{t}, I_{t}\right\}$, the value function iteration method is not applicable. Aruoba, FernandezVillaverde and F. (2006) show that the solutions based on the second-order perturbation method can be fairly accurate compared to those based on the method of value function iteration.
} 
variables are given by

$$
\begin{aligned}
\tilde{N}_{t}: & \left(1+\frac{1}{\varpi_{1} \tilde{D}_{t}}\right)\left[e^{X_{t}}\left(1-2 h \tilde{S}_{t}\right)-H_{t}\right]=\beta \mathbb{E}_{t}\left\{\left(1+\frac{1}{\varpi_{1} \tilde{D}_{t+1}}\right)\left[e^{X_{t+1}}\left(1-2 h \tilde{S}_{t+1}\right)-G_{t+1}\right]\right\} \\
\tilde{Q}_{t}: & \left(1+\frac{1}{\varpi_{1} \tilde{D}_{t}}\right)\left[e^{X_{t}}\left(1-2 h \tilde{S}_{t}\right)-e^{Z_{t}}\left(d_{1}+d_{2} \tilde{Q}_{t}\right)-G_{t}\right]=\frac{1}{\left[\varpi_{2}\left(A_{0} \tilde{K}_{t-1}^{\alpha} g^{-\alpha}-\tilde{Q}_{t}\right)\right]} \\
\tilde{I}_{t}: & \left(1+\frac{1}{\varpi_{1} \tilde{D}_{t}}\right)\left[1+a g\left(\frac{\tilde{I}_{t}}{\tilde{K}_{t-1}}\right)\right]=\beta \mathbb{E}_{t}\left\{g\left(1+\frac{1}{\varpi_{1} \tilde{D}_{t+1}}\right)\right. \\
\times & {\left[\frac{a}{2} g\left(\frac{\tilde{I}_{t+1}}{\tilde{K}_{t}}\right)^{2}-f_{1}+(1-\delta) g^{-1}\left(1+a g\left(\frac{\tilde{I}_{t+1}}{\tilde{K}_{t}}\right)\right)\right] } \\
+g & {\left.\left[\frac{\alpha \tilde{K}_{t}^{\alpha-1} g^{-\alpha}}{\varpi_{2}\left(A_{0} \tilde{K}_{t}^{\alpha} g^{-\alpha}-\tilde{Q}_{t+1}\right)}\right]\right\}, }
\end{aligned}
$$

where

$$
\begin{aligned}
& H_{t}=\frac{b \gamma}{2} \tilde{S}_{t}^{\gamma-1}\left(1-\frac{c \tilde{N}_{t}}{\tilde{S}_{t}}\right)^{2}+b c \tilde{S}_{t}^{\gamma-2}\left(\tilde{N}_{t}+\tilde{S}_{t}\right)\left(1-\frac{c \tilde{N}_{t}}{\tilde{S}_{t}}\right) \\
& G_{t}=\frac{b \gamma}{2} \tilde{S}_{t}^{\gamma-1}\left(1-\frac{c \tilde{N}_{t}}{\tilde{S}_{t}}\right)^{2}+b c \tilde{S}_{t}^{\gamma-2} \tilde{N}_{t}\left(1-\frac{c \tilde{N}_{t}}{\tilde{S}_{t}}\right) .
\end{aligned}
$$

For financially unconstrained firms, let $\varpi_{1} \rightarrow \infty$ and we get

$$
\begin{aligned}
\tilde{N}_{t}: & {\left[e^{X_{t}}\left(1-2 h \tilde{S}_{t}\right)-H_{t}\right]=\beta \mathbb{E}_{t}\left\{\left[e^{X_{t+1}}\left(1-2 h \tilde{S}_{t+1}\right)-G_{t+1}\right]\right\} } \\
\tilde{Q}_{t}: & {\left[e^{X_{t}}\left(1-2 h \tilde{S}_{t}\right)-e^{Z_{t}}\left(d_{1}+d_{2} \tilde{Q}_{t}\right)-G_{t}\right]=\frac{1}{\left[\varpi_{2}\left(A_{0} \tilde{K}_{t-1}^{\alpha} g^{-\alpha}-\tilde{Q}_{t}\right)\right]} } \\
\tilde{I}_{t}: & {\left[1+a g\left(\frac{\tilde{I}_{t}}{\tilde{K}_{t}}\right)\right]=\beta \mathbb{E}_{t}\left\{g \times\left[\frac{a}{2} g\left(\frac{\tilde{I}_{t+1}}{\tilde{K}_{t}}\right)^{2}-f_{1}\right.\right.} \\
& \left.\left.+(1-\delta) g^{-1}\left(1+a g\left(\frac{\tilde{I}_{t+1}}{\tilde{K}_{t}}\right)\right)\right]+g\left[\frac{\alpha \tilde{K}_{t}^{\alpha-1} g^{-\alpha}}{\varpi_{2}\left(A_{0} \tilde{K}_{t}^{\alpha} g^{-\alpha}-\tilde{Q}_{t+1}\right)}\right]\right\} .
\end{aligned}
$$

The above two sets of system equations are solved using second-order perturbation method. 


\section{B Variable Definitions}

\begin{tabular}{|c|c|}
\hline Variable & Description \\
\hline$F C$ & $\begin{array}{l}\text { Dummy that equals to } 1 \text { if the firm is a financially constrained firm, and zero } \\
\text { otherwise. FCs in the simulated data are firms whose dividend have to be non- } \\
\text { negative and in the real data are classified based on size }\end{array}$ \\
\hline FCrating & $\begin{array}{l}\text { Dummy that equals to } 1 \text { if the firm does not have any rating throughout the } \\
\text { sample period, and } 0 \text { if the firm has either a bond rating or commercial paper } \\
\text { rating in any given year }\end{array}$ \\
\hline$F C h p$ & $\begin{array}{l}\text { Dummy that equals to } 1 \text { if the Hadlock-Pierce Index is above the top } 30 \text { th per- } \\
\text { centile in the quarter, and } 0 \text { if it is below the bottom } 30 \text { th percentile }\end{array}$ \\
\hline$F C w w$ & $\begin{array}{l}\text { Dummy that equals to } 1 \text { if the Whited-Wu Index is above the top quartile in the } \\
\text { quarter, and } 0 \text { if it is below the bottom quartile in the quarter }\end{array}$ \\
\hline$K$ & $\begin{array}{l}\text { Level of beginning-of-period capital defined as capital stock in the simulated data } \\
\text { and as total asset (ATQ) minus inventory (INVTQ) in the actual data }\end{array}$ \\
\hline$N / K$ & $\begin{array}{l}\text { Inventory scaled by } K \text {, where inventory in the simulated data is the stock of goods } \\
\text { firms carry priced at market value, and in the actual data is INVTQ adjusted for } \\
\text { the LIFO and FIFO accounting following Salinger and Summers (1983). }\end{array}$ \\
\hline N_Growth & Change in inventory scaled by $K$. \\
\hline$S / K$ & $\begin{array}{l}\text { Sales scaled by } K \text {, where sales in the simulated data is the dollar value of sales } \\
\text { and in the actual data is SALEQ }\end{array}$ \\
\hline S_Growth & $\begin{array}{l}\text { Change in sales scaled by } K \text {, where sales in the simulated data is the dollar value } \\
\text { of sales and in the actual data is SALEQ }\end{array}$ \\
\hline$S_{-} G r o w t h^{+}$ & $\begin{array}{l}\text { Interaction of } S_{-} G r o w t h \text { and an indicator which equals to } 1 \text { if } S_{-} G r o w t h \text { is posi- } \\
\text { tive, and } 0 \text { otherwise }\end{array}$ \\
\hline S_Growth ${ }^{-}$ & $\begin{array}{l}\text { Interaction of } S_{-} G r o w t h \text { and an indicator which equals to } 1 \text { if } S \_G r o w t h \text { is neg- } \\
\text { ative, and } 0 \text { otherwise }\end{array}$ \\
\hline$I / K$ & $\begin{array}{l}\text { Investment-to-lagged capital ratio, where investment in the simulated data is } \\
\text { the change of capital net of depreciation and in the actual data is calculated by } \\
\text { converting the Compustat Year-to-Date item CAPXY to quarterly frequency }\end{array}$ \\
\hline PPE_Growth & Change in property, plant and equipment (PPENTQ) scaled by $K$ \\
\hline$K_{-}$Growth & Change in $\mathrm{K}$ scaled by $K$ \\
\hline$C F / K$ & $\begin{array}{l}\text { Cash flow scaled by } K \text {, where cash flow in the simulated data is calculated by } \\
\text { subtracting production cost, operating cost, and investment adjustment cost from } \\
\text { sales, and in the actual data is defined as earnings before extraordinary items } \\
\text { (IBQ) plus depreciation (DPQ) }\end{array}$ \\
\hline$Q / K$ & (simulated data only) Production scaled by $K$ \\
\hline Utilization & $\begin{array}{l}\text { (simulated data only) Proportion of capital that firms actually used to generate } \\
\text { output over the total } K\end{array}$ \\
\hline
\end{tabular}




\begin{tabular}{|c|c|}
\hline Variable & Description \\
\hline Cost & $\begin{array}{l}\text { (simulated data only) Negative of the cost realization, higher value indi- } \\
\text { cating a more favorable state }\end{array}$ \\
\hline Demand & (simulated data only) Realization of demand \\
\hline CostShock & $\begin{array}{l}\text { Change in level of (negative) cost realization scaled by its standard devi- } \\
\text { ation in the simulated data, and (the negative of) percentage change in } \\
\text { the Intermediate Input Price Index in the actual data }\end{array}$ \\
\hline CostShock $^{+}$ & $\begin{array}{l}\text { Interaction of CostShock with an indicator that equals to } 1 \text { if CostShock } \\
\text { is favorable (positive in the simulated data, and above industry median } \\
\text { in the actual data), and } 0 \text { otherwise }\end{array}$ \\
\hline CostShock ${ }^{-}$ & $\begin{array}{l}\text { Interaction of CostShock with an indicator that equals to } 1 \text { if CostShock } \\
\text { is unfavorable (negative in the simulated data, and below industry me- } \\
\text { dian in the actual data), and } 0 \text { otherwise }\end{array}$ \\
\hline DemandShock & $\begin{array}{l}\text { Change in level of demand realization scaled by its standard deviation in } \\
\text { the simulated data }\end{array}$ \\
\hline DemandShock $^{+}$ & $\begin{array}{l}\text { Interaction of DemandShock with an indicator that equals to } 1 \text { if } \\
\text { DemandShock is positive, and } 0 \text { otherwise }\end{array}$ \\
\hline DemandShock ${ }^{-}$ & $\begin{array}{l}\text { Interaction of DemandShock with an indicator that equals to } 1 \text { if } \\
\text { DemandShock is negative, and } 0 \text { otherwise }\end{array}$ \\
\hline$A d v$ & $\begin{array}{l}\text { Dummy that equals to } 1 \text { if the (cost, demand or sales) shock is below the } \\
\text { 20th percentile of its distribution, and zero otherwise. }\end{array}$ \\
\hline Fav & $\begin{array}{l}\text { Dummy that equals to } 1 \text { if the (cost, demand or sales) shock is above the } \\
\text { 80th percentile of its distribution, and zero otherwise }\end{array}$ \\
\hline After & $\begin{array}{l}\text { Dummy equals to } 1 \text { for the quarters 1990Q2 to 1990Q4 (1990Q2 to } \\
\text { 1993Q4) for the short (long) run window, and zero for the period from } \\
\text { 1986Q1 to 1989Q4. }\end{array}$ \\
\hline Preshock & $\begin{array}{l}\text { Dummy that equals to } 1 \text { if the observation is in the three quarters before } \\
\text { the shock (1989Q1 to 1989Q3) }\end{array}$ \\
\hline BelowInvestment & $\begin{array}{l}\text { Dummy that equals to } 1 \text { if the firm has a below-investment-grade debt } \\
\text { rating (BB }+ \text { or lower) in the quarterly }\end{array}$ \\
\hline Northeast & $\begin{array}{l}\text { Dummy that equals to } 1 \text { if the firm is located in the Northeast region } \\
\text { of the United States, which includes Maine, New Hampshire, Vermont, } \\
\text { Massachusetts, Rhode Island, Connecticut, New York, New Jersey, and } \\
\text { Pennsylvania, and } 0 \text { otherwise. The location information, obtained from } \\
\text { Bill McDonald's website, is based on headers for 10-K forms from } 1994 \\
\text { to 2010. For the period before 1994, the } 1994 \text { location is assigned. }\end{array}$ \\
\hline
\end{tabular}




\section{Table 1: Baseline Calibration}

This table lists the parameter values used to solve and simulate the baseline model. The capital-to-output ratio $\alpha$ is from Hennessy and Whited (2007). The growth rate of productivity $g$ is chosen to match the average aggregate growth rate of sales in our sample. The discount factor $\beta$ is set to match the quarterly interest rate. Capital depreciation rate $\delta$ and investment adjustment cost parameter $a$ are chosen to match the mean and volatility of investment-to-capital ratio, respectively. The slope of the demand curve $h$ is chosen to generate an average markup in Altig et al. (2011). The scaling factor $A_{0}$ in the capacity constraint is chosen to match the average capacity utilization rate from the IHS Global Insight dataset for the sample period 1971 - 2010. The stockout avoidance cost ratio $c$ is set to match the mean of inventory-to-capital ratio. The long-run mean of demand $\bar{X}$ is chosen so that the average capital level is one. The volatility of idiosyncratic demand and shocks $\sigma_{X}$ and $\sigma_{Z}$ are set to match the time-series average of the cross-sectional standard deviation of sales-to-capital ratio. The remaining 9 parameters, the stockout avoidance cost parameter $b$, elasticity of stockout-avoidance cost to sales $\gamma$, production cost parameters $d_{1}$ and $d_{2}$, the persistences of idiosyncratic cost and demand shocks $\rho_{Z}$ and $\rho_{X}$, the moving average coefficient $\rho_{\varepsilon}$ and the operating cost parameters $f_{0}$ and $f_{1}$, are chosen to match the means and volatilities of sales-to-capital ratio, sales change-to-capital ratio, and inventory change-to-capital ratio, the volatility of inventory-to-capital ratio, the autocorrelations of sales-to-capital ratio, and the ratio of the volatility of aggregate output to the volatility of aggregate sales. Details of how the model is calibrated can be found in Section 2.2. Parameters are reported at quarterly frequency.

\begin{tabular}{ccl}
\hline Parameter & Value & Description \\
\hline$\alpha$ & 0.7 & Capital-to-output ratio \\
$g$ & 1.009 & Growth rate of productivity \\
$\beta$ & 0.982 & Time-preference coefficient \\
$\delta$ & 0.015 & Capital depreciation rate \\
$a$ & 60 & Quadratic investment adjustment cost \\
$h$ & 0.01 & Slope of demand curve \\
$A_{0}$ & 3 & Scaling factor in capacity constraint \\
$c$ & 2.08 & Stockout-avoidance ratio \\
$b$ & 0.0032 & Stockout-avoidance cost \\
$\gamma$ & 1.5 & Elasticity of stockout-avoidance cost to sales \\
$d_{1}$ & 0.132 & Linear production cost \\
$d_{2}$ & 0.022 & Quadratic production cost \\
$f_{0}$ & 0.0665 & Fixed operating cost \\
$f_{1}$ & 0.0069 & Linear operating cost \\
$\rho_{Z}$ & 0.92 & Persistence coefficient of cost shock \\
$\sigma_{Z}$ & 0.137 & Conditional volatility of cost shock \\
$\bar{X}$ & -1.45 & Long-run average of demand shock \\
$\rho_{\varepsilon}$ & 0.11 & Moving average coefficient \\
$\rho_{X}$ & 0.93 & Persistence coefficient of demand shock \\
$\sigma_{X}$ & 0.035 & Conditional volatility of demand shock \\
\hline
\end{tabular}




\section{Table 2: Comparative Statics}

This table presents the comparative statics for our baseline model. Parameters of interest include fixed operating cost $f_{0}$, quadratic investment adjustment cost $a$, the conditional volatility of cost shock and demand shock $\sigma_{Z}$ and $\sigma_{X}$. More detailed descriptions of the baseline calibration are included in Table 1 and Section 2.2. The top row shows the parameter value in the baseline calibration. The row beneath shows the corresponding new value. In column (1) to (4), one parameter value is changed each time while others are fixed at the baseline value. Moments include mean and standard deviation (in bracket) of the capital level $\left(K_{t}\right)$, inventory level $\left(N_{t}\right)$ and inventory-tocapital ratio $\left(N_{t} / K_{t}\right)$. Moments under baseline parameters are reported first, followed by the ones generated from the new value. For each of these moments, we listed the value for UFC, FC and the difference between the two groups. The level variables $K$ and $N$ are divided by the corresponding level of UFC in the baseline and multiplied by 100 . All results obtained use the same realization of shocks.

\begin{tabular}{|c|c|c|c|c|c|}
\hline & & $(1)$ & $(2)$ & $(3)$ & $(4)$ \\
\hline Variable & Baseline & high $f_{0}$ & high $a_{0}$ & $\operatorname{high} \sigma_{Z}$ & high $\sigma_{X}$ \\
\hline Baseline Value & & $f_{0}=0.0665$ & $a_{0}=60$ & $\sigma_{Z}=0.137$ & $\sigma_{X}=0.035$ \\
\hline New Value & & $f_{0}=0.0760$ & $a_{0}=90$ & $\sigma_{Z}=0.177$ & $\sigma_{X}=0.050$ \\
\hline \multicolumn{6}{|c|}{$K_{t}($ UFC's capital in the baseline $=100)$} \\
\hline \multirow[t]{2}{*}{ UFC } & 100 & 100 & 79 & 109 & 105 \\
\hline & [100] & [100] & {$[79]$} & {$[111]$} & {$[106]$} \\
\hline \multirow[t]{2}{*}{$\mathrm{FC}$} & 84 & 81 & 66 & 84 & 86 \\
\hline & [85] & {$[83]$} & {$[66]$} & {$[87]$} & {$[88]$} \\
\hline \multirow[t]{2}{*}{ Diff(UFC-FC) } & 16 & 19 & 13 & 25 & 19 \\
\hline & {$[15]$} & {$[17]$} & [12] & {$[25]$} & [18] \\
\hline \multicolumn{6}{|c|}{$N_{t}($ UFC's inventory in the baseline $=100)$} \\
\hline \multirow[t]{2}{*}{ UFC } & 100 & 100 & 86 & 97 & 101 \\
\hline & {$[100]$} & [100] & [84] & [103] & [102] \\
\hline \multirow[t]{2}{*}{$\mathrm{FC}$} & 132 & 154 & 95 & 168 & 141 \\
\hline & [153] & [189] & [151] & [218] & [169] \\
\hline \multirow[t]{2}{*}{ Diff(UFC-FC) } & -32 & -52 & -10 & -66 & -39 \\
\hline & {$[-53]$} & {$[-89]$} & {$[-66]$} & {$[-115]$} & {$[-67]$} \\
\hline \multicolumn{6}{|l|}{$N_{t} / K_{t}$} \\
\hline \multirow[t]{2}{*}{ UFC } & 0.150 & 0.150 & 0.162 & 0.134 & 0.145 \\
\hline & {$[0.050]$} & {$[0.050]$} & {$[0.048]$} & {$[0.058]$} & {$[0.054]$} \\
\hline \multirow[t]{2}{*}{$\mathrm{FC}$} & 0.225 & 0.269 & 0.273 & 0.282 & 0.235 \\
\hline & {$[0.136]$} & {$[0.181]$} & {$[0.176]$} & {$[0.215]$} & {$[0.152]$} \\
\hline \multirow[t]{2}{*}{ Diff(UFC-FC) } & -0.075 & -0.119 & -0.111 & -0.148 & -0.090 \\
\hline & {$[-0.086]$} & {$[-0.131]$} & {$[-0.128]$} & {$[-0.157]$} & {$[-0.098]$} \\
\hline
\end{tabular}




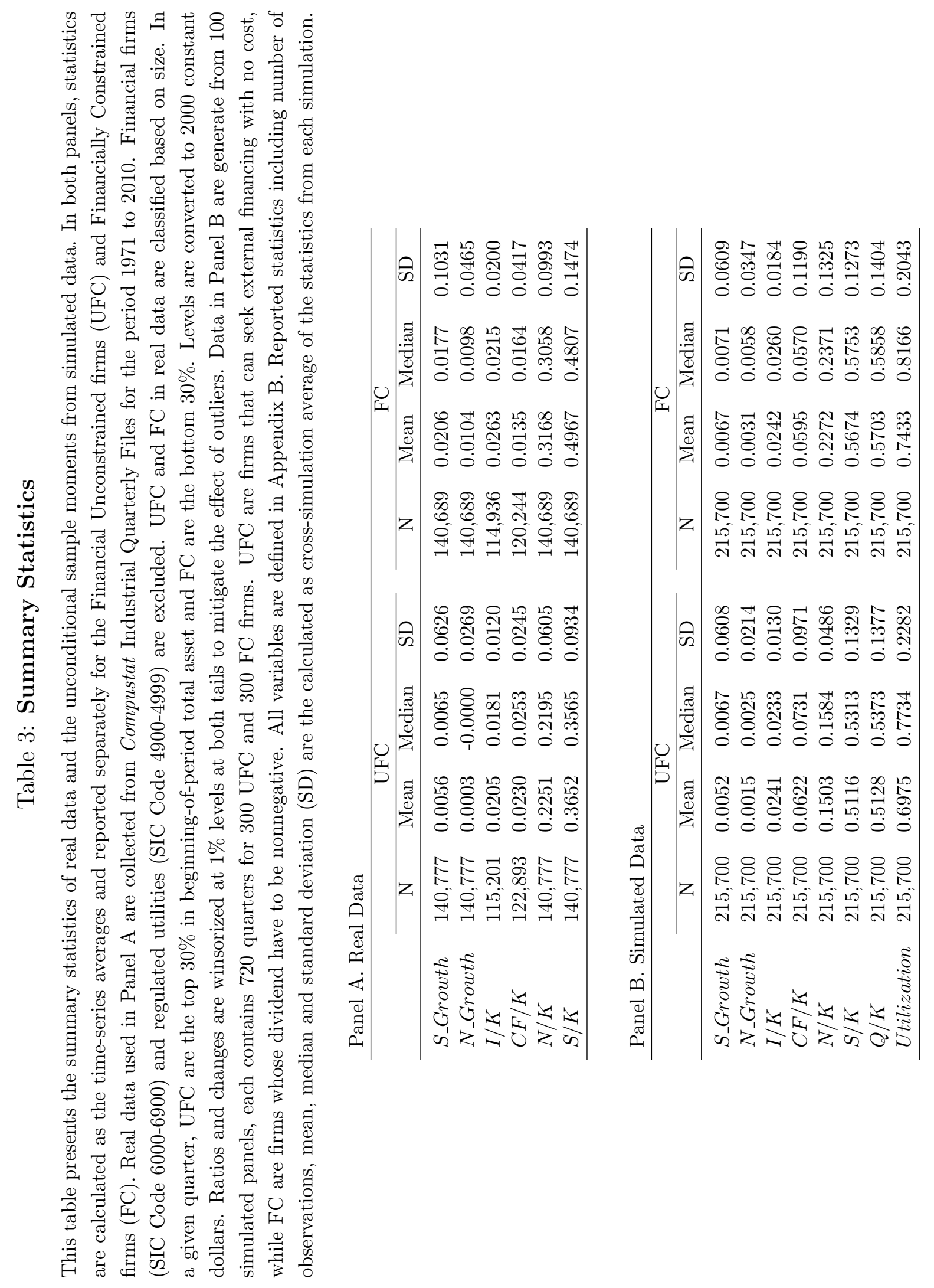




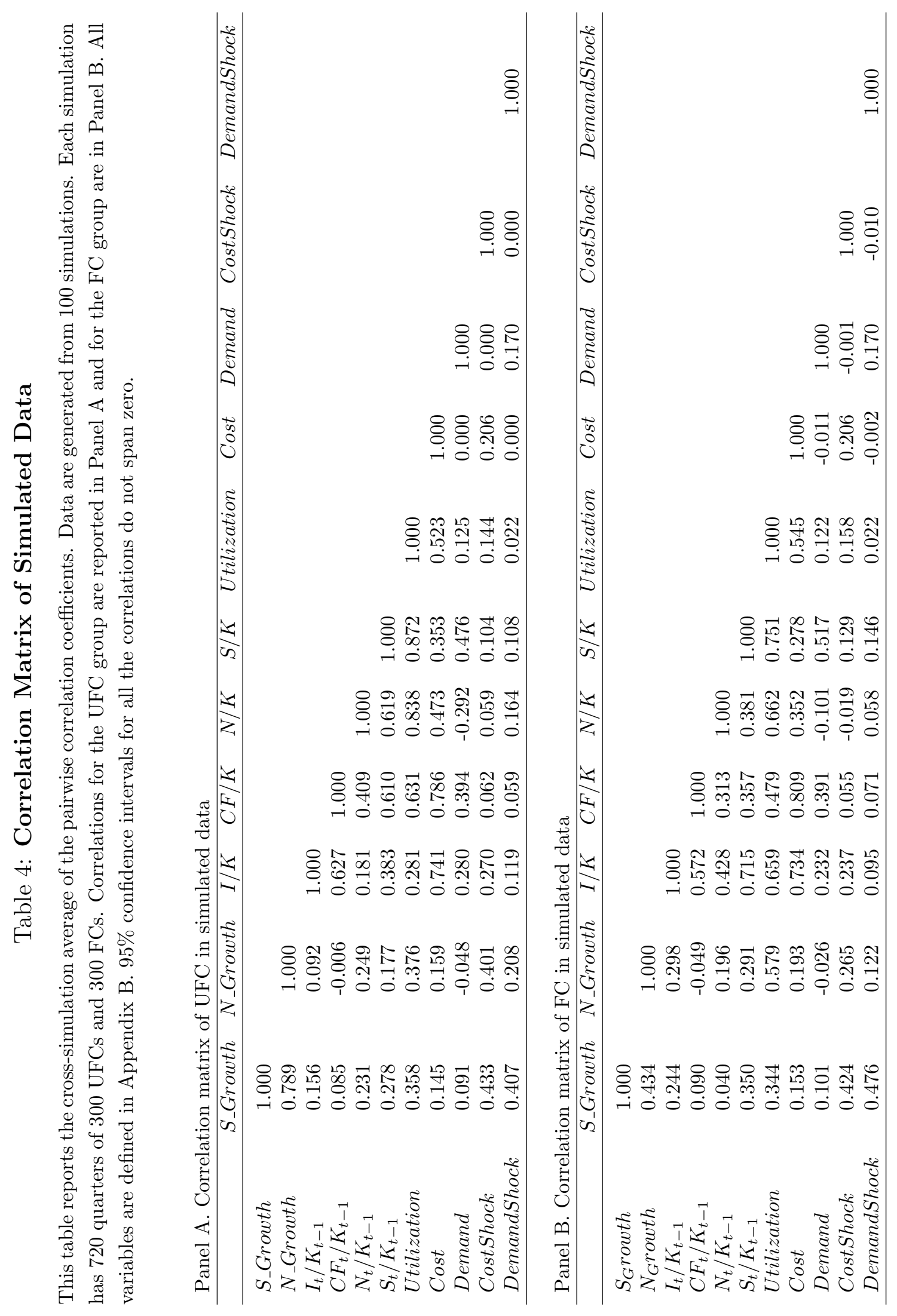




\section{Table 5: Regression on Shocks with Simulated Data}

This table reports the regression results of the asymmetric response (Panel A) and dynamic adjustment (Panel B) on the simulated data. All variables are defined in Appendix B The dependent variable is N_Growth. CostShock $k_{t}^{+} \times$ $F C$, CostShock $k_{t}^{-} \times F C$, DemandShock $t_{t}^{+} \times F C$ and DemandShock ${ }_{t}^{-} \times F C$ are the interactions of CostShock ${ }_{t}^{+}$, CostShock $_{t}^{-}$,DemandShock $t_{t}^{+}$and DemandShock $k_{t}^{-}$with the $F C$ dummy. In Panel B, we create indicator variables,

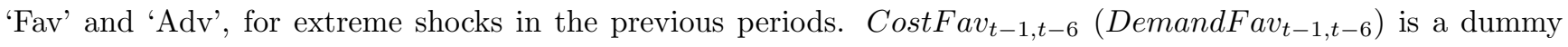
that equals to 1 if the average cost (demand) shocks over the past 6 periods is in the top 20th percentile of the distribution, and 0 otherwise. Cost $A d v_{t-1, t-6}$ (Demand $A d v_{t-1, t-6}$ ) is a dummy equals to 1 if the average cost (demand) shocks over the past 6 periods is in the bottom 20th percentile of the distribution, and 0 otherwise. We also include their interactions with the $F C$ dummy. The simulated data are generate from 100 simulations. Cross-simulation average of regression coefficients are reported. $95 \%$ confidence intervals are included in brackets and coefficients are marked with $* * *$ if $95 \%$ confidence intervals do not span zero.

Panel A: The Asymmetric Response on Model-generated Data

\begin{tabular}{|c|c|c|c|}
\hline & $\stackrel{(1)}{N \_ \text {Growth }}$ & $\begin{array}{c}(2) \\
N_{-} \text {Growth } \\
.\end{array}$ & $\begin{array}{c}(3) \\
N \_ \text {Growth }\end{array}$ \\
\hline$F C$ & $\begin{array}{c}0.0081^{* * *} \\
{[0.0080,0.0082]}\end{array}$ & $\begin{array}{c}0.0073^{* * *} \\
{[0.0072,0.0075]}\end{array}$ & $\begin{array}{c}0.0042^{* * *} \\
{[0.0040,0.0044]}\end{array}$ \\
\hline CostShock $_{t}^{+}$ & $\begin{array}{c}0.0085^{* * *} \\
{[0.0084,0.0085]}\end{array}$ & $\begin{array}{c}0.0084^{* * *} \\
{[0.0084,0.0085]}\end{array}$ & \\
\hline CostShock $_{t}^{+} \times F C$ & $\begin{array}{c}-0.0039^{* * *} \\
{[-0.0041,-0.0036]}\end{array}$ & $\begin{array}{c}-0.0039^{* * *} \\
{[-0.0040,-0.0038]}\end{array}$ & \\
\hline CostShock ${ }_{t}^{-}$ & $\begin{array}{c}0.0098^{* * *} \\
{[0.0098,0.0099]}\end{array}$ & $\begin{array}{c}0.0099^{* * *} \\
{[0.0098,0.0099]}\end{array}$ & \\
\hline CostShock $_{t}^{-} \times F C$ & $\begin{array}{c}0.0052^{* * *} \\
{[0.0045,0.0060]}\end{array}$ & $\begin{array}{c}0.0048^{* * *} \\
{[0.0047,0.0049]}\end{array}$ & \\
\hline DemandShock $_{t}^{+}$ & $\begin{array}{c}0.0047^{* * *} \\
{[0.0047,0.0047]}\end{array}$ & & $\begin{array}{c}0.0047^{* * *} \\
{[0.0047,0.0047]}\end{array}$ \\
\hline DemandShock $_{t}^{+} \times F C$ & $\begin{array}{c}-0.0005^{* * *} \\
{[-0.0008,-0.0002]}\end{array}$ & & $\begin{array}{c}-0.0007^{* * *} \\
{[-0.0010,-0.0005]}\end{array}$ \\
\hline DemandShock $k_{t}^{-}$ & $\begin{array}{c}0.0037^{* * *} \\
{[0.0037,0.0037]}\end{array}$ & & $\begin{array}{c}0.0037^{* * *} \\
{[0.0036,0.0037]}\end{array}$ \\
\hline DemandShock $_{t}^{-} \times F C$ & $\begin{array}{c}0.0005^{* * *} \\
{[0.0003,0.0007]}\end{array}$ & & $\begin{array}{c}0.0003^{* * *} \\
{[0.0003,0.0004]}\end{array}$ \\
\hline Cost $_{t-1}$ & $\begin{array}{c}0.0038^{* * *} \\
{[0.0038,0.0038]}\end{array}$ & $\begin{array}{c}0.0036^{* * *} \\
{[0.0036,0.0037]}\end{array}$ & \\
\hline Demand $_{t-1}$ & $\begin{array}{c}-0.0022^{* * *} \\
{[-0.0023,-0.0022]}\end{array}$ & & $\begin{array}{c}-0.0022^{* * *} \\
{[-0.0022,-0.0021]}\end{array}$ \\
\hline$N_{t-1} / K_{t-2}$ & $\begin{array}{c}-0.0362^{* * *} \\
{[-0.0365,-0.0358]}\end{array}$ & $\begin{array}{c}-0.0311^{* * *} \\
{[-0.0315,-0.0308]}\end{array}$ & $\begin{array}{c}-0.0276^{* * *} \\
{[-0.0279,-0.0274]}\end{array}$ \\
\hline Constant & $\begin{array}{c}0.0388^{* * *} \\
{[0.0387,0.0390]}\end{array}$ & $\begin{array}{c}0.0168^{* * *} \\
{[0.0166,0.0170]}\end{array}$ & $\begin{array}{c}0.0257^{* * *} \\
{[0.0251,0.0263]}\end{array}$ \\
\hline $\begin{array}{l}\text { Observations } \\
\text { Adj. } R^{2}\end{array}$ & $\begin{array}{c}430,800 \\
0.155\end{array}$ & $\begin{array}{c}430,800 \\
0.125\end{array}$ & $\begin{array}{c}430,800 \\
0.037\end{array}$ \\
\hline
\end{tabular}


Panel B: The Dynamics of Inventory Adjustment on Model-generated Data

\begin{tabular}{|c|c|c|c|}
\hline & $\begin{array}{c}(1) \\
N_{-} \text {Growth } \\
\end{array}$ & $\begin{array}{c}(2) \\
N_{-} \text {Growth } \\
.\end{array}$ & $\begin{array}{c}(3) \\
N_{-} \text {Growt } h_{t} \\
\end{array}$ \\
\hline$F C_{t}$ & $\begin{array}{c}-0.0079^{* * *} \\
{[-0.0079,-0.0080]}\end{array}$ & $\begin{array}{c}-0.0072^{* * *} \\
{[-0.0071,-0.0073]}\end{array}$ & $\begin{array}{c}0.0041^{* * *} \\
{[0.0040,0.0043]}\end{array}$ \\
\hline CostShock $_{t}^{+}$ & $\begin{array}{c}0.0077^{* * *} \\
{[0.0077,0.0078]}\end{array}$ & $\begin{array}{c}0.0077^{* * *} \\
{[0.0077,0.0078]}\end{array}$ & \\
\hline CostShock $_{t}^{+} \times F C$ & $\begin{array}{c}-0.0023^{* * *} \\
{[-0.0027,-0.0019]}\end{array}$ & $\begin{array}{c}-0.0025^{* * *} \\
{[-0.0025,-0.0024]}\end{array}$ & \\
\hline CostShock- & $\begin{array}{c}0.0102^{* * *} \\
{[0.1020,0.1020]}\end{array}$ & $\begin{array}{c}0.0102^{* * *} \\
{[0.1020,0.1020]}\end{array}$ & \\
\hline CostShock $k_{t}^{-} \times F C$ & $\begin{array}{c}0.0045^{* * *} \\
{[0.0037,0.0053]}\end{array}$ & $\begin{array}{c}0.0041^{* * *} \\
{[0.0040,0.0042]}\end{array}$ & \\
\hline $\operatorname{CostFav}_{t-1, t-6}$ & $\begin{array}{c}0.0017^{* * *} \\
{[0.0017,0.0017]}\end{array}$ & $\begin{array}{c}0.0015^{* * *} \\
{[0.0015,0.0016]}\end{array}$ & \\
\hline $\operatorname{CostFav}_{t-1, t-6} \times F C$ & $\begin{array}{c}0.0042^{* * *} \\
{[0.0040,0.0044]}\end{array}$ & $\begin{array}{c}0.0042^{* * *} \\
{[0.0041,0.0044]}\end{array}$ & \\
\hline $\operatorname{Cost} A d v_{t-1, t-6}$ & $\begin{array}{c}-0.0023^{* * *} \\
{[-.0 . .23,-0.0023]}\end{array}$ & $\begin{array}{c}-0.0023^{* * *} \\
{[-0.0023,-0.0023]}\end{array}$ & \\
\hline $\operatorname{Cost}_{A d v_{t-1, t-6}} \times F C$ & $\begin{array}{c}-0.0081^{* * *} \\
{[-0.0083,-0.0079]}\end{array}$ & $\begin{array}{c}-0.0081^{* * *} \\
{[-0.0083,-0.0079]}\end{array}$ & \\
\hline DemandShock $_{t}^{+}$ & $\begin{array}{c}0.0048^{* * *} \\
{[0.0048,0.0048]}\end{array}$ & & $\begin{array}{c}0.0048^{* * *} \\
{[0.0048,0.0048]}\end{array}$ \\
\hline DemandShock $_{t}^{+} \times F C$ & $\begin{array}{c}-0.0005^{* * *} \\
{[-0.0008,-0.0002]}\end{array}$ & & $\begin{array}{c}-0.0008^{* * *} \\
{[-0.0010,-0.0005]}\end{array}$ \\
\hline DemandShock $_{t}^{-}$ & $\begin{array}{c}0.0037^{* * *} \\
{[0.0037,0.0037]}\end{array}$ & & $\begin{array}{c}0.0037^{* * *} \\
{[0.0037,0.0037]}\end{array}$ \\
\hline DemandShock $_{t}^{-} \times F C$ & $\begin{array}{c}0.0006^{* *} \\
{[0.0002,0.0010]}\end{array}$ & & $\begin{array}{c}0.0004^{* *} \\
{[0.0003,0.0005]}\end{array}$ \\
\hline $\operatorname{DemandFav}_{t-1, t-6}$ & $\begin{array}{c}-0.0055^{* * *} \\
{[-0.0055,-0.0055]}\end{array}$ & & $\begin{array}{c}-0.0055^{* * *} \\
{[-0.0055,-0.0054]}\end{array}$ \\
\hline DemandFav $_{t-1, t-6} \times F C$ & $\begin{array}{c}0.0008^{* * *} \\
{[0.0007,0.0009]}\end{array}$ & & $\begin{array}{c}0.0008^{* * *} \\
{[0.0005,0.0010]}\end{array}$ \\
\hline Demand Adv $v_{t-1, t-6}$ & $\begin{array}{c}0.0039^{* * *} \\
{[0.0039,0.0039]}\end{array}$ & & $\begin{array}{c}0.0040^{* * *} \\
{[0.0039,0.0040]}\end{array}$ \\
\hline $\operatorname{Demand} A d v_{t-1, t-6} \times F C$ & $\begin{array}{c}-0.0011^{* * *} \\
{[-0.0012,-0.0009]}\end{array}$ & & $\begin{array}{c}-0.0011^{* * *} \\
{[-0.0011,-0.0011]}\end{array}$ \\
\hline Other Controls & Yes & Yes & Yes \\
\hline Observations & 430,800 & 430,800 & 430,800 \\
\hline $\operatorname{Adj} . R^{2}$ & 0.178 & 0.140 & 0.045 \\
\hline
\end{tabular}




\section{Table 6: The Asymmetric Response on Actual Data}

This table reports the regression results on the asymmetric response of inventory growth to cost shocks using the real data. All variables are defined in Appendix B. Observations are at annual frequency. Cost shock is measured by the negative percentage change in Chain-Type Price Indexes for intermediate input by industry provided by the Bureau of Economic Analysis. The dependent variable is $N_{-}$Growth. We use four commonly used financial constraint classifications: total assets in column (1), ratings in column (2), the Hadlock-Pierce Index in column (3), and the Whited-Wu Index in column (4). CostShock ${ }_{t}^{+} \times F C_{t}$ and CostShock ${ }_{t}^{-} \times F C_{t}$ are the interactions of CostShock ${ }_{t}^{+}$and $C_{\text {ostShock }}^{-}$with the $F C_{t}$ dummy. The regressions also control for $(C F / K)_{t-1}$, $(C F / K)_{t-1} \times F C_{t}, K_{-}$Growth and $(N / K)_{t-1}$, and are estimated with firm-fixed effects and year-fixed effects. t-statistics in parentheses are adjusted using the Huber-White estimator allowing within firm clusters to avoid potential heteroskedasticity and serial correlation. Coefficients significant at the $10 \%, 5 \%$, and $1 \%$ levels are marked with *,**, and ${ }^{* * *}$, respectively.

\begin{tabular}{|c|c|c|c|c|}
\hline & $\begin{array}{c}(1) \\
N_{-} \text {Growth }_{t}\end{array}$ & $\begin{array}{c}(2) \\
N_{-} \text {Growth }_{t}\end{array}$ & $\begin{array}{c}(3) \\
N \_ \text {Growth }_{t}\end{array}$ & $\begin{array}{c}(4) \\
N_{-} \text {Growth } \\
\end{array}$ \\
\hline FC Classification & Total Assets & Ratings & HP Index & WW Index \\
\hline$F C$ & $\begin{array}{c}0.0263^{* * *} \\
(5.31)\end{array}$ & $\begin{array}{l}- \\
-\end{array}$ & $\begin{array}{c}0.0118^{* * *} \\
(3.62)\end{array}$ & $\begin{array}{c}-0.0357^{* * *} \\
(-11.99)\end{array}$ \\
\hline CostShock ${ }_{t}^{+}$ & $\begin{array}{c}0.0308^{* * *} \\
(2.80)\end{array}$ & $\begin{array}{c}0.0502^{* * *} \\
(4.38)\end{array}$ & $\begin{array}{c}0.0250^{*} \\
(1.83)\end{array}$ & $\begin{array}{c}0.0180 \\
(1.33)\end{array}$ \\
\hline CostShock $_{t}^{+} \times F C_{t}$ & $\begin{array}{c}-0.0658^{* * *} \\
(-3.06)\end{array}$ & $\begin{array}{c}-0.0493^{* * * *} \\
(-2.89)\end{array}$ & $\begin{array}{c}-0.0416^{*} \\
(-1.92)\end{array}$ & $\begin{array}{c}-0.0236 \\
(-0.98)\end{array}$ \\
\hline CostShock ${ }_{t}^{-}$ & $\begin{array}{c}-0.0444^{* * *} \\
(-5.24)\end{array}$ & $\begin{array}{c}-0.0335^{* * *} \\
(-3.79)\end{array}$ & $\begin{array}{c}-0.0333^{* * *} \\
(-3.72)\end{array}$ & $\begin{array}{c}-0.0508^{* * *} \\
(-5.55)\end{array}$ \\
\hline CostShock $_{t}^{-} \times F C_{t}$ & $\begin{array}{c}0.0680^{* * *} \\
(4.25)\end{array}$ & $\begin{array}{c}0.0242^{* *} \\
(1.96)\end{array}$ & $\begin{array}{c}0.0334^{* *} \\
(2.03)\end{array}$ & $\begin{array}{c}0.0960^{* * *} \\
(5.28)\end{array}$ \\
\hline$(C F / K)_{t-1}$ & $\begin{array}{c}0.145^{* * *} \\
(11.61)\end{array}$ & $\begin{array}{c}0.130^{* * *} \\
(13.80)\end{array}$ & $\begin{array}{c}0.152^{* * *} \\
(12.47)\end{array}$ & $\begin{array}{c}0.130^{* * *} \\
(15.79)\end{array}$ \\
\hline$(C F / K)_{t-1} \times F C_{t}$ & $\begin{array}{c}-0.0258^{*} \\
(-1.87)\end{array}$ & $\begin{array}{c}0.00312 \\
(0.28)\end{array}$ & $\begin{array}{c}-0.0394^{* * *} \\
(-2.97)\end{array}$ & $\begin{array}{c}-0.0549^{* * *} \\
(-5.71)\end{array}$ \\
\hline K_Growth & $\begin{array}{c}0.0628^{* * *} \\
(31.16)\end{array}$ & $\begin{array}{c}0.0750^{* * *} \\
(43.81)\end{array}$ & $\begin{array}{c}0.0673^{* * *} \\
(33.51)\end{array}$ & $\begin{array}{c}0.0550^{* * *} \\
(28.45)\end{array}$ \\
\hline$N_{t-1} / K_{t-2}$ & $\begin{array}{c}-0.0608^{* * *} \\
(-9.43)\end{array}$ & $\begin{array}{c}-0.0466^{* * *} \\
(-9.97)\end{array}$ & $\begin{array}{c}-0.0644^{* * *} \\
(-10.33)\end{array}$ & $\begin{array}{c}-0.0701 * * * \\
(-11.35)\end{array}$ \\
\hline Constant & $\begin{array}{c}-0.0109^{* *} \\
(-2.09)\end{array}$ & $\begin{array}{c}-0.00624 \\
(-1.49)\end{array}$ & $\begin{array}{c}-0.000360 \\
(-0.07)\end{array}$ & $\begin{array}{c}0.00735 \\
(1.18)\end{array}$ \\
\hline Observations & 85429 & 127120 & 85637 & 71115 \\
\hline $\operatorname{Adj} \cdot R^{2}$ & 0.119 & 0.138 & 0.122 & 0.137 \\
\hline
\end{tabular}




\section{Table 7: Sales Growth as a Proxy for Cost and Demand Shocks}

This table reports the regression results when using quarterly sales growth to proxy for cost and demand shocks. Variables are defined in Appendix B. Column (1) and (2) examine of quality of sales growth as a proxy for both types of shocks. The dependent variable is S_Growth. Column (3) and (4) test the asymmetric response and dynamic inventory adjustment in response to sales growth. The dependent variable is N_Growth. To test the asymmetric response, we create a dummy, $A d v_{t-1}$, to capture the extreme adverse (sales) states. It equals to 1 if $S_{-}$Growt $_{t-1}$ is below the 20th percentile of the firm's sales growth distribution, and zero otherwise. To test the dynamic inventory adjustment, we create two dummies variables, $F a v_{t-1, t-6}$ and $A d v_{t-1, t-6}$, for extreme (sales) shocks in the previous periods. $F_{a v_{t-1, t-6}}\left(A d v_{t-1, t-6}\right)$ equals to 1 if the average sales growth over the past 6 periods is in the top (bottom) 20th percentile of the moving-average distribution, and 0 otherwise. The reported estimates are the cross-simulation average of the coefficients from 100 simulations. 95\% confidence intervals are included in brackets and coefficients are marked with *** if $95 \%$ confidence intervals do not span zero.

\begin{tabular}{|c|c|c|c|c|}
\hline & \multicolumn{2}{|c|}{ Sales Growth on Shocks } & \multicolumn{2}{|c|}{ Inventory Growth on Sales Growth } \\
\hline & $\begin{array}{c}(1) \\
\text { S_Growth }\end{array}$ & $\begin{array}{c}(2) \\
\text { S_Growth }\end{array}$ & $\begin{array}{c}(3) \\
N \_G r o w t h\end{array}$ & $\begin{array}{c}(4) \\
\text { N_Growth }\end{array}$ \\
\hline CostShock & $\begin{array}{c}0.0264^{* * *} \\
{[0.0263,0.0264]}\end{array}$ & & & \\
\hline CostShock $\times F C$ & $\begin{array}{c}0.0005 \\
{[-0.0009,0.0003]}\end{array}$ & & & \\
\hline DemandShock & & $\begin{array}{c}0.0248^{* * *} \\
{[0.0247,0.0248]}\end{array}$ & & \\
\hline DemandShock $\times F C$ & & $\begin{array}{c}0.0044^{* * *} \\
{[0.0040,0.0048]}\end{array}$ & & \\
\hline S_Growth $^{+}$ & & & $\begin{array}{c}0.223^{* * *} \\
{[0.222,0.223]}\end{array}$ & $\begin{array}{c}0.216^{* * *} \\
{[0.215,0.216]}\end{array}$ \\
\hline$S_{-} G r o w t h^{+} \times F C_{t}$ & & & $\begin{array}{c}-0.154^{* * *} \\
{[-0.159,-0.149]}\end{array}$ & $\begin{array}{c}-0.144^{* * *} \\
{[-0150,-0.138]}\end{array}$ \\
\hline S_Growth ${ }^{-}$ & & & $\begin{array}{c}0.332^{* * *} \\
{[0.331,0.332]}\end{array}$ & $\begin{array}{c}0.333^{* * *} \\
{[0.333,0.334]}\end{array}$ \\
\hline$S_{-} G r o w t h^{-} \times F C_{t}$ & & & $\begin{array}{c}0.111^{* * *} \\
{[0.110,0.113]}\end{array}$ & $\begin{array}{c}0.118^{* * *} \\
{[0.116,0.120]}\end{array}$ \\
\hline$A d v_{t-1}$ & & & $\begin{array}{c}0.0028^{* * *} \\
{[0.0027,0.0028]}\end{array}$ & \\
\hline$A d v_{t-1} \times F C$ & & & $\begin{array}{c}-0.0168^{* * *} \\
{[-0.0171,-0.0165]}\end{array}$ & \\
\hline Fav $_{t-1, t-6}$ & & & & $\begin{array}{c}-0.001^{* * *} \\
{[-0.002,-0.001]}\end{array}$ \\
\hline$F_{a v} v_{t, t-6} \times F C$ & & & & $\begin{array}{c}0.0077^{* * *} \\
{[0.0075,0.0078]}\end{array}$ \\
\hline$A d v_{t-1, t-6}$ & & & & $\begin{array}{c}-0.0021^{* * *} \\
{[-0.0021,-0.0021]}\end{array}$ \\
\hline$A d v_{t-1, t-6} \times F C$ & & & & $\begin{array}{c}-0.0113^{* * *} \\
{[-0.0115,-0.0111]}\end{array}$ \\
\hline Other Controls & Yes & Yes & Yes & Yes \\
\hline Observations & 431,400 & 431,400 & 430,800 & 430,800 \\
\hline $\operatorname{Adj} . R^{2}$ & 0.186 & 0.196 & 0.367 & 0.372 \\
\hline
\end{tabular}




\section{Table 8: Input Price Changes at Quarterly Frequency and Instrumented Sales Growth}

This table reports the regression results when using quarterly oil price changes (Panel A) and input prices based on the IO table and PPI (Panel B) to instrument sales growth to test the asymmetric response and dynamic adjustment of inventory growth to cost shocks. We obtain daily prices of crude oil from Bloomberg and use price on the last trading day in each month to calculate the percentage change in oil prices at monthly frequency. We then deflate the price changes and compute the cumulative real price changes over three months. The price changes are matched to the Compustat firms based on the end date of each fiscal quarter and are multiplied by - 1 to make positive (negative) price changes to reflect favorable (unfavorable) cost shocks. We constructed another measure of cost shock at quarterly frequency based on the Input-Output table and the output price indices at the industry level. For our 71 NAICS industries, the (summary-level use table before redefinitions data in the 2007) Input-Output table provides the input (supplier) industries from which they use goods and service from and the corresponding flows between the customer and supplier industries. We calculate the percentage of inputs from each supplier industry's output to the total inputs of the customer industry, and use this to weigh the output price indices of the supplier industries, which are based on the Producer Price Index (PPI) provided by the Bureau of Labor Statistics and covers all industries in the goods-producing sectors of the U.S. at monthly frequency. For each product, we compute the percentage change in output prices in each month and average across all products within the industry. We then adjust for inflation and compound the output price changes to quarterly frequency. To instrument sales growth with our measures of cost shocks, for each industry, we regress sales growth at quarter $t$ on the (negative of) oil price changes at $t-2$ and its interaction with the $F C$ dummy, controlling for $(C F / K)_{t-1}$, its interaction with the $F C$ dummy, $K_{-} G r o w t h_{t}$ and firm-fixed effect. We lag the oil price changes by two quarters since on average it takes 2 quarters for the sales growth to react positively to the oil price changes. The control variables are defined in Appendix B. We use the predicted sales growth to determine whether firms experience favorable or unfavorable cost shocks and perform the same test as we did on the simulated data in Table 5. For Panel A, we only keep industries for which there is a positive relationship between sales growth and oil price changes. The results on the asymmetric response are reported in column (1) to (4) and dynamic adjustment in column (5) to (8). The dependent variable is $N_{-}$Growth. To test the asymmetric response, we create a dummy, $A d v_{t-1}$, to capture the extreme adverse cost states. It equals to 1 if the predicted sales growth is below the 20th percentile of the firm's distribution, and zero otherwise. To test the dynamic inventory adjustment, we create two dummies variables, $F a v_{t-1, t-6}$ and $A d v_{t-1, t-6}$, for extreme cost shocks in the previous periods. Fav $_{t-1, t-6}\left(A d v_{t-1, t-6}\right)$ equals to 1 if the average predicted sales growth over the past 6 periods is in the top (bottom) 20th percentile of the moving-average distribution, and 0 otherwise. The regressions also control for $(C F / K)_{t-1},(C F / K)_{t-1} \times F C_{t}, K_{-} G r o w t h$ and $(N / K)_{t-1}$, and are estimated with firm-fixed effects and year-fixed effects. We use four commonly used financial constraint classifications: total assets in column (1) and (5), ratings in column (2) and (6), the Hadlock-Pierce Index in column (3) and (7), and the Whited-Wu Index in column (4) and (8). The regression model is run for each quarter to account for seasonality. The reported coefficients are the average coefficient over the four quarters. t-statistics in parentheses are calculated using the Fama-MacBeth method. Coefficients significant at the 10\%, $5 \%$, and $1 \%$ levels are marked with ${ }^{* * *}$, and ${ }^{* * *}$, respectively. The original regressions on each quarter are available upon request. 
Panel A: Evidence from Oil Price Changes

\begin{tabular}{|c|c|c|c|c|c|c|c|c|}
\hline & \multicolumn{4}{|c|}{ Asymmetric Response } & \multicolumn{4}{|c|}{ Dynamic Adjustment } \\
\hline & $\begin{array}{c}(1) \\
N \_ \text {Growth }\end{array}$ & $\begin{array}{c}(2) \\
N_{-} \text {Growth }\end{array}$ & $\begin{array}{c}(3) \\
N_{-} \text {Growtht }\end{array}$ & $\begin{array}{c}(4) \\
N_{-} \text {Growth }\end{array}$ & $\begin{array}{c}(5) \\
N_{-} \text {Growth }_{t}\end{array}$ & $\begin{array}{c}(6) \\
N_{-} \text {Growth }\end{array}$ & $\begin{array}{c}(7) \\
N_{-} \text {Growth } \\
\end{array}$ & $\begin{array}{c}(8) \\
N_{-} \text {Growtht }\end{array}$ \\
\hline FC Classification & Total Asset & Rating & HP Index & WW Index & Total Asset & Rating & HP Index & WW Index \\
\hline$S_{-} \widehat{\text { Grow }} t h_{t}^{+}$ & $\begin{array}{c}0.110^{* *} \\
(4.1)\end{array}$ & $\begin{array}{c}0.127^{* * *} \\
(6.26)\end{array}$ & $\begin{array}{c}0.159^{* *} \\
(3.52)\end{array}$ & $\begin{array}{c}0.092^{* * *} \\
(5.36)\end{array}$ & $\begin{array}{c}0.099^{* *} \\
(4.05)\end{array}$ & $\begin{array}{l}0.119^{* * *} \\
\quad(6.4)\end{array}$ & $\begin{array}{c}0.158^{* *} \\
(3.75)\end{array}$ & $\begin{array}{c}0.090^{* *} \\
(5.65)\end{array}$ \\
\hline$S_{-} \widehat{\text { Grow }} h_{t}^{+} \times F C_{t}$ & $\begin{array}{c}-0.083^{* *} \\
(-3.67)\end{array}$ & $\begin{array}{c}-0.067^{* *} \\
(-4.97)\end{array}$ & $\begin{array}{c}-0.173^{* *} \\
(-3.79)\end{array}$ & $\begin{array}{c}-0.079 * * * \\
(-3.44)\end{array}$ & $\begin{array}{c}-0.060^{*} \\
(-2.93)\end{array}$ & $\begin{array}{c}-0.049^{* *} \\
(-4.16)\end{array}$ & $\begin{array}{c}-0.162^{* *} \\
(-3.93)\end{array}$ & $\begin{array}{c}-0.067^{*} \\
(-3.17)\end{array}$ \\
\hline$S_{-} \widehat{\text { Grow }} t h_{t}^{-}$ & $\begin{array}{l}0.001 \\
(0.25)\end{array}$ & $\begin{array}{c}-0.028^{* *} \\
(-4.11)\end{array}$ & $\begin{array}{c}-0.020^{* * *} \\
(-7.58)\end{array}$ & $\begin{array}{l}0.005 \\
(1.06)\end{array}$ & $\begin{array}{c}-0.0003 \\
(-0.06)\end{array}$ & $\begin{array}{l}-0.025 \\
(-3.9)\end{array}$ & $\begin{array}{c}-0.021^{* * *} \\
(-6.21)\end{array}$ & $\begin{array}{l}0.006 \\
(1.24)\end{array}$ \\
\hline$S_{-} \widehat{\text { Grow }} h_{t}^{-} \times F C_{t}$ & $\begin{array}{c}-0.00357 \\
(-0.38)\end{array}$ & $\begin{array}{l}-0.024 \\
(-1.98)\end{array}$ & $\begin{array}{l}-0.027^{*} \\
(-2.72)\end{array}$ & $\begin{array}{l}-0.038 \\
(-3.53)\end{array}$ & $\begin{array}{c}-0.023^{* *} \\
(-3.63)\end{array}$ & $\begin{array}{l}-0.023 \\
(-1.93)\end{array}$ & $\begin{array}{l}-0.021 \\
(-2.22)\end{array}$ & $\begin{array}{c}0.035^{* *} \\
(-3.29)\end{array}$ \\
\hline$A d v_{t-1}$ & $\begin{array}{c}-0.0006^{*} \\
(-2.83)\end{array}$ & $\begin{array}{c}-0.0013^{* *} \\
(-4.17)\end{array}$ & $\begin{array}{c}-0.0004 \\
(-0.93)\end{array}$ & $\begin{array}{c}-0.0003 \\
(-0.55)\end{array}$ & & & & \\
\hline$A d v_{t-1} \times F C_{t}$ & $\begin{array}{c}-0.0035^{* * *} \\
(-10.35)\end{array}$ & $\begin{array}{l}-0.0025^{* * *} \\
(-5.05)\end{array}$ & $\begin{array}{c}-0.0043^{* * *} \\
(-13.4)\end{array}$ & $\begin{array}{c}-0.0036^{* *} \\
(-5.68)\end{array}$ & & & & \\
\hline $\operatorname{Fav}_{t-1, t-6}$ & & & & & $\begin{array}{c}0.0001 \\
(0.21)\end{array}$ & $\begin{array}{l}0.0011 \\
(2.15)\end{array}$ & $\begin{array}{l}0.0001 \\
(0.49)\end{array}$ & $\begin{array}{l}0.0000 \\
(-0.07)\end{array}$ \\
\hline$F a v_{t-1, t-6} \times F C_{t}$ & & & & & $\begin{array}{c}0.0012^{*} \\
(2.67)\end{array}$ & $\begin{array}{c}0.0016^{* * *} \\
(6.27)\end{array}$ & $\begin{array}{c}0.0031^{* * *} \\
(19.43)\end{array}$ & $\begin{array}{c}0.0017^{*} \\
(3.07)\end{array}$ \\
\hline$A d v_{t-1, t-6}$ & & & & & $\begin{array}{l}-0.0004 \\
(-2.42)\end{array}$ & $\begin{array}{c}-0.0016^{* *} \\
(-1.97)\end{array}$ & $\begin{array}{l}-0.0006 \\
(-2.25)\end{array}$ & $\begin{array}{l}0.0000 \\
(-6.27)\end{array}$ \\
\hline$A d v_{t-1, t-6} \times F C_{t}$ & & & & & $\begin{array}{c}-0.0049 * * \\
(-5.55)\end{array}$ & $\begin{array}{l}-0.0015 \\
(-2.17)\end{array}$ & $\begin{array}{c}-0.0052^{* *} \\
(-5.59)\end{array}$ & $\begin{array}{c}-0.0037^{* * *} \\
(-7.5)\end{array}$ \\
\hline Other Controls & Yes & Yes & Yes & Yes & Yes & Yes & Yes. & Yes \\
\hline Observations & 48,448 & 70,065 & 48,328 & 37945 & 48703 & 70217 & 48583 & 38539 \\
\hline $\operatorname{Adj} . R^{2}$ & 0.299 & 0.328 & 0.311 & 0.320 & 0.305 & 0.33 & 0.316 & 0.324 \\
\hline
\end{tabular}


Panel B: Evidence from Inferred Input Price Changes

\begin{tabular}{|c|c|c|c|c|c|c|c|c|}
\hline & \multicolumn{4}{|c|}{ Asymmetric Response } & \multicolumn{4}{|c|}{ Dynamic Adjustment } \\
\hline & $\begin{array}{c}(1) \\
N_{-} \text {Growt }_{t}\end{array}$ & $\begin{array}{c}(2) \\
N_{-} \text {Growth } \\
\end{array}$ & $\begin{array}{c}(3) \\
N_{-} \text {Growth }\end{array}$ & $\begin{array}{c}(4) \\
N_{-} \text {Growth } \\
\end{array}$ & $\begin{array}{c}(5) \\
N_{-} \text {Growt } h_{t}\end{array}$ & $\begin{array}{c}(6) \\
N_{-} \text {Growth }\end{array}$ & $\begin{array}{c}(7) \\
N_{-} G r o w t h_{t}\end{array}$ & $\begin{array}{c}(8) \\
N_{-} \text {Growtht }\end{array}$ \\
\hline FC Classification & Total Asset & Rating & HP Index & WW Index & Total Asset & Rating & HP Index & WW Index \\
\hline S_ $\widehat{\text { Grow }} t h_{t}^{+}$ & $\begin{array}{c}0.135^{* * *} \\
(7.16)\end{array}$ & $\begin{array}{c}0.107^{* *} \\
(5.5)\end{array}$ & $\begin{array}{c}0.170^{* * *} \\
(10.0)\end{array}$ & $\begin{array}{c}0.092^{* *} \\
(4.96)\end{array}$ & $\begin{array}{c}0.125^{* * *} \\
(7.43)\end{array}$ & $\begin{array}{c}0.097^{* *} \\
(4.89)\end{array}$ & $\begin{array}{c}0.171^{* * *} \\
(11.49)\end{array}$ & $\begin{array}{c}0.093^{* * *} \\
(6.33)\end{array}$ \\
\hline$S_{-} \widehat{\text { Grow }} t h_{t}^{+} \times F C_{t}$ & $\begin{array}{c}-0.135^{* * *} \\
(-7.16)\end{array}$ & $\begin{array}{c}-0.089^{* * *} \\
(-9.04)\end{array}$ & $\begin{array}{c}-0.213^{* * *} \\
(-11.15)\end{array}$ & $\begin{array}{c}-0.131^{* * *} \\
(-12.02)\end{array}$ & $\begin{array}{c}-0.133^{* * *} \\
(-6.83)\end{array}$ & $\begin{array}{c}-0.072^{* * *} \\
(-7.94)\end{array}$ & $\begin{array}{c}-0.206^{* * *} \\
(-13.52)\end{array}$ & $\begin{array}{c}-0.121^{* * *} \\
(-26.67)\end{array}$ \\
\hline$S_{-} \widehat{\text { Grow }} h_{t}^{-}$ & $\begin{array}{l}-0.010 \\
(-0.19)\end{array}$ & $\begin{array}{l}-0.108 \\
(-2.25)\end{array}$ & $\begin{array}{l}-0.033 \\
(-0.77)\end{array}$ & $\begin{array}{l}0.036 \\
(0.71)\end{array}$ & $\begin{array}{l}-0.010 \\
(-0.22)\end{array}$ & $\begin{array}{l}-0.107 \\
(-2.27)\end{array}$ & $\begin{array}{l}-0.031 \\
(-0.74)\end{array}$ & $\begin{array}{c}0.04 \\
(0.87)\end{array}$ \\
\hline$S_{-} \widehat{\text { Grow }} t h_{t}^{-} \times F C_{t}$ & $\begin{array}{l}-0.091 \\
(-1.69)\end{array}$ & $\begin{array}{l}-0.013 \\
(-0.25)\end{array}$ & $\begin{array}{l}-0.069 \\
(-1.24)\end{array}$ & $\begin{array}{l}-0.138 \\
(-3.24)\end{array}$ & $\begin{array}{c}-0.089 \\
(-1.8)\end{array}$ & $\begin{array}{l}-0.016 \\
(-0.32)\end{array}$ & $\begin{array}{l}-0.074 \\
(-1.47)\end{array}$ & $\begin{array}{c}-0.140^{* *} \\
(-3.57)\end{array}$ \\
\hline$A d v_{t-1}$ & $\begin{array}{c}-0.0004 \\
(-1.57)\end{array}$ & $\begin{array}{c}-0.0013^{*} \\
(-2.3)\end{array}$ & $\begin{array}{c}0 \\
(0.02)\end{array}$ & $\begin{array}{c}0.0004 \\
(0.81)\end{array}$ & & & & \\
\hline$A d v_{t-1} \times F C_{t}$ & $\begin{array}{c}-0.0029 * * \\
(-5.08)\end{array}$ & $\begin{array}{c}-0.0019^{* * *} \\
(-4.42)\end{array}$ & $\begin{array}{c}-0.0042^{* * *} \\
(-8.55)\end{array}$ & $\begin{array}{c}-0.0038^{* *} \\
(-4.01)\end{array}$ & & & & \\
\hline $\mathrm{Fav}_{t-1, t-6}$ & & & & & $\begin{array}{c}-0.0002 \\
(-0.46)\end{array}$ & $\begin{array}{c}0.0012 \\
(1.71)\end{array}$ & $\begin{array}{c}-0.0003 \\
(-0.43)\end{array}$ & $\begin{array}{c}-0.0001 \\
(-0.29)\end{array}$ \\
\hline$F a v_{t-1, t-6} \times F C_{t}$ & & & & & $\begin{array}{c}0.0034^{* * *} \\
(6.84)\end{array}$ & $\begin{array}{c}0.0023^{* * *} \\
(8.36)\end{array}$ & $\begin{array}{c}0.0055^{* * *} \\
(5.77)\end{array}$ & $\begin{array}{c}0.0037^{* * *} \\
(8.65)\end{array}$ \\
\hline$A d v_{t-1, t-6}$ & & & & & $\begin{array}{c}0.0003 \\
(0.6)\end{array}$ & $\begin{array}{c}-0.0017^{* * *} \\
(-4.21)\end{array}$ & $\begin{array}{c}0.0004 \\
(0.84)\end{array}$ & $\begin{array}{c}0.0009^{* *} \\
(2.3)\end{array}$ \\
\hline$A d v_{t-1, t-6} \times F C_{t}$ & & & & & $\begin{array}{c}-0.0039^{*} \\
(-3.04)\end{array}$ & $\begin{array}{c}-0.0011 \\
(-1.42)\end{array}$ & $\begin{array}{c}-0.0061^{* * *} \\
(-22.51)\end{array}$ & $\begin{array}{c}-0.0047^{* * *} \\
(-3.84)\end{array}$ \\
\hline Other Controls & Yes & Yes & Yes & Yes & Yes & Yes & Yes. & Yes \\
\hline Observations & 58,559 & 85,701 & 58,477 & 45,841 & 58879 & 85884 & 58777 & 46595 \\
\hline $\operatorname{Adj} . R^{2}$ & 0.361 & 0.39 & 0.368 & 0.376 & 0.364 & 0.391 & 0.371 & 0.379 \\
\hline
\end{tabular}




\section{Table 9: The Response of Inventory Growth To Credit Shocks}

This table reports the response of inventory growth to the shock on firms' financial constraints status. The sample consists of all the unrated firms and firms with a below-investment-grade debt rating ( $\mathrm{BB}+$ or lower) in the quarterly Compustat database during the period 1986 to 1993. Panel A reports the impact of the credit shock on the response of inventory growth of the below-investment-grade firms vis-a-vis that of matched unrated firms. Panel B explores geographic variation as another source of variation and reports the impact of the credit shock on the response of inventory growth of firms located in the Northeast region of the United States vis-a-vis that of firms located elsewhere. The control firms in both tests are matched with the treated firms on industry and size. We use the 1994 location information obtained from Bill McDonald's website, which is based on headers for 10-K forms in 1994 to 2010. The event quarter is 1990Q1. Therefore, the Before window is from 1986Q1 to 1989Q4, and the After window is from1990Q2 to 1990Q4 (1990Q2 to 1993Q4) for the short-run (long-run) window. We require each firm contain at least one observation in both the before and after period. We control for the trend before the shock Preshock, which is a dummy that equals to 1 if the observation is in the three quarters before the shock (1989Q1 to 1989Q3). We partition firms into favorable and unfavorable shock states based on the industry annual input price change for the three years before the credit shock as well as the three years after. The dependent variable is $N_{-}$Growt $h_{t}$. All the other variables are defined in Appendix B. The regression model is estimated with firm-fixed effect. t-statistics are reported in parentheses. Coefficients significant at the $10 \%, 5 \%$, and $1 \%$ levels are marked with $*^{* *}$, and ${ }^{* * *}$, respectively. The standard errors are reported in the parentheses. For the differences, ${ }^{*}, * *$, and ${ }^{* *}$ indicate statistical significance at the $10 \%, 5 \%$, and $1 \%$ levels based on one-tail distribution.

Panel A: The Impact on Below-Investment-Grade Firms

\begin{tabular}{|c|c|c|c|c|}
\hline & \multicolumn{2}{|c|}{ Favorable Cost Shocks } & \multicolumn{2}{|c|}{ Unfavorable Cost Shocks } \\
\hline & $\begin{array}{c}\text { short-run } \\
(1) \\
N_{-} \text {Growth }\end{array}$ & $\begin{array}{c}\text { long-run } \\
(2) \\
N_{\text {_Growth }}\end{array}$ & $\begin{array}{c}\text { short-run } \\
(3) \\
N_{-} \text {Growth }\end{array}$ & $\begin{array}{c}\text { long-run } \\
\quad(4) \\
N_{-} \text {Growtht }\end{array}$ \\
\hline After $_{t}$ & $\begin{array}{c}0.00377 \\
(0.56)\end{array}$ & $\begin{array}{c}0.000395 \\
(0.10)\end{array}$ & $\begin{array}{c}0.00193 \\
(0.24)\end{array}$ & $\begin{array}{c}0.00124 \\
(0.32)\end{array}$ \\
\hline After $_{t} \times$ BelowInvestment & $\begin{array}{c}-0.0324^{* *} \\
(-2.39)\end{array}$ & $\begin{array}{c}-0.0171^{*} \\
(-1.87)\end{array}$ & $\begin{array}{c}-0.0154 \\
(-1.43)\end{array}$ & $\begin{array}{c}-0.0132^{*} \\
(-1.95)\end{array}$ \\
\hline Preshock $_{t}$ & $\begin{array}{c}-0.0126 \\
(0.42)\end{array}$ & $\begin{array}{c}-0.0104 \\
(-0.57)\end{array}$ & $\begin{array}{c}-0.00862 \\
(0.54)\end{array}$ & $\begin{array}{c}-0.0101 \\
(0.72)\end{array}$ \\
\hline Preshock $_{t} \times$ BelowInvestment & $\begin{array}{c}-0.00646 \\
(-1.56)\end{array}$ & $\begin{array}{c}-0.00455 \\
(-1.39)\end{array}$ & $\begin{array}{c}-0.00244 \\
(-0.85)\end{array}$ & $\begin{array}{c}-0.00234 \\
(-1.07)\end{array}$ \\
\hline $\log (K)_{t}$ & $\begin{array}{c}-0.0821^{* * *} \\
(-4.38)\end{array}$ & $\begin{array}{c}-0.0437^{* * *} \\
(-4.26)\end{array}$ & $\begin{array}{c}-0.0430^{* *} \\
(-2.63)\end{array}$ & $\begin{array}{c}-0.0313^{* *} \\
(-2.30)\end{array}$ \\
\hline Constant & $\begin{array}{c}0.569^{* * *} \\
(4.49)\end{array}$ & $\begin{array}{c}0.312^{* * *} \\
(4.45)\end{array}$ & $\begin{array}{c}0.291^{* *} \\
(2.66)\end{array}$ & $\begin{array}{c}0.213^{* *} \\
(2.32)\end{array}$ \\
\hline Observations & 1367 & 2255 & 511 & 864 \\
\hline $\operatorname{Adj} . R^{2}$ & 0.089 & 0.093 & 0.019 & 0.010 \\
\hline
\end{tabular}


Panel B: Geographic Variation in the Response to Credit Shocks

\begin{tabular}{|c|c|c|c|c|}
\hline & \multicolumn{2}{|c|}{ Favorable Cost Shocks } & \multicolumn{2}{|c|}{ Unfavorable Cost Shocks } \\
\hline & $\begin{array}{c}\text { short-run } \\
\quad(1) \\
N_{-} \text {Growt } h_{t}\end{array}$ & $\begin{array}{c}\text { long-run } \\
(2) \\
N_{-} \text {Growt } h_{t}\end{array}$ & $\begin{array}{c}\text { short-run } \\
(3) \\
N_{-} \text {Growth }\end{array}$ & $\begin{array}{c}\text { long-run } \\
\quad(4) \\
N_{-} G r o w t h_{t}\end{array}$ \\
\hline After $_{t}$ & $\begin{array}{c}-0.0031 \\
(-0.75)\end{array}$ & $\begin{array}{c}-0.0058^{* *} \\
(-2.30)\end{array}$ & $\begin{array}{c}-0.0157^{* * *} \\
(-4.50)\end{array}$ & $\begin{array}{c}-0.0056^{* * *} \\
(-2.72)\end{array}$ \\
\hline After $_{t} \times$ Northeast & $\begin{array}{c}-0.0123^{* *} \\
(-2.06)\end{array}$ & $\begin{array}{c}-0.0045 \\
(-1.23)\end{array}$ & $\begin{array}{c}-0.0006 \\
(-0.13)\end{array}$ & $\begin{array}{c}-0.0052^{*} \\
(-1.81)\end{array}$ \\
\hline Preshock $_{t}$ & $\begin{array}{c}0.0009 \\
(0.26)\end{array}$ & $\begin{array}{c}-0.00002 \\
(-0.01)\end{array}$ & $\begin{array}{c}-0.0084^{* * *} \\
(-2.74)\end{array}$ & $\begin{array}{c}-0.0082^{* * *} \\
(-2.81)\end{array}$ \\
\hline Preshock $_{t} \times$ Northeast & $\begin{array}{c}-0.0040 \\
(-0.75)\end{array}$ & $\begin{array}{c}-0.0042 \\
(-0.81)\end{array}$ & $\begin{array}{c}0.0010 \\
(0.23)\end{array}$ & $\begin{array}{c}0.0004 \\
(0.10)\end{array}$ \\
\hline $\log (K)_{t}$ & $\begin{array}{c}-0.0400 * * * \\
(-10.24)\end{array}$ & $\begin{array}{c}-0.0296^{* * *} \\
(-11.93)\end{array}$ & $\begin{array}{c}-0.0330^{* * *} \\
(-9.21)\end{array}$ & $\begin{array}{c}-0.0235^{* * *} \\
(-11.00)\end{array}$ \\
\hline Constant & $\begin{array}{c}0.220^{* * *} \\
(10.84)\end{array}$ & $\begin{array}{c}0.165^{* * *} \\
(12.86)\end{array}$ & $\begin{array}{c}0.164^{* * *} \\
(9.75)\end{array}$ & $\begin{array}{c}0.120^{* * *} \\
(11.84)\end{array}$ \\
\hline $\begin{array}{l}\text { Observations } \\
A d i R^{2}\end{array}$ & 5,613 & $\begin{array}{l}9,306 \\
0,038\end{array}$ & 6,345 & 10,673 \\
\hline
\end{tabular}

